\title{
TIPOLOGÍA SOCIAL DE UNA OLIGARQUÍA URBANA: LOS REGIDORES DE GUADALAJARA EN EL SIGLO XVIII. ¿ELITE NOBILIARIA O BURGUESÍA FUNCIONARIAL?
}

por

\author{
FÉLIX SALGADo Olmeda \\ Doctor en Historia Moderna
}

RESUMEN: Durante el Antiguo Régimen español las ciudades castellanas, especialmente las de voto en Cortes, cabezas de provincia fiscal y militar, fueron regidas por oligarquías $y$ grupos medios urbanos que las consideraron un coto cerrado en el que no siempre ejercieron la acción municipal, sino que, frecuentemente, fueron una plataforma para sus deseos de ascenso social.

La propiedad del regimiento, vía "venalidad", les hacía pertenecer a una «elite de poder» político en el ámbito urbano y les proporcionaba, además de oficios y empleos, la gestión (y a veces la privatización en sus personas —vía juros o deuda pública municipal $\rightarrow$ de numerosos recursos fiscales municipales $y$ de rentas reales, como el servicio, los millones, los cientos, o las alcabalas, pero también les daba a ellos y a sus familiares el tan ansiado prestigio social, que en la España Moderna venía asociado a la condición nobiliaria.

Un estudio del grupo, el origen social y económico, las expectativas de ascenso y promoción social es lo que se pretende en este artículo con el caso concreto de los regidores de Guadalajara en el siglo XVIII.

Palabras Clave: Antiguo Régimen. Ciudades castellanas. Oligarquía urbana. Elite de poder. Origen social. Regidores de Guadalajara. Ascenso social.

ABSTRACT: During the Spanish ancien regime, Castilian cities, above all those with the right to vote in the Cortes and the centres of military and fiscal provinces, were ruled by oligarchies and intermediate urban classes who regarded them as a private property in which those in authority rarely performed their legal office and instead considered them as a means of upward social mobility. The venality of local office placed them in a political elite in the urban environment, provided them with important positions, and autbority over substantial local fiscal resources and royal income such as servicios, millones, cientos, and alcabalas. In addition, political 
power provided much-desired social prestige, which was commonly associated with the status of nobility. This article addresses the social and economic origin, the and expectations of upward social mobility, of eigbteenth-century regidores in Guadalajara.

KEY WORDS: Cities. Oligarchies. Urban society. Political elite. Social origin. Regidores. Guadalajara. Social mobility.

Son numerosos los estudios sobre la naturaleza social de las elites económicas, administrativas y urbanas en la España del Antiguo Régimen ${ }^{1}$, empezando por el ya clásico estudio de Janine Fayard sobre los consejeros de Castilla en los siglos XVII y XVIII ${ }^{2}$, hasta las más recientes investigaciones sobre las oligarquías municipales de importantes ciudades castellanas como $\mathrm{Madrid}^{3}$, Toledo ${ }^{4}$, Murcia $^{5}$, Granada ${ }^{6}$, de Cataluña ${ }^{7}$ o las del Reino de Valencia ${ }^{8}$.

¿Burguesía?, ¿nobleza?. En una sociedad como la del Antiguo Régimen en la que el puesto que se ocupaba en la estructura social venía claramente definido por elementos y privilegios diferenciadores del status, (fundamentalmente legales y jurídicos) y por su poder político, más que por el nivel de rentas y

1 Véase en este sentido Maravall, J.A.: Poder, honor y elites en el siglo XVII. Madrid, 1989. Domínguez ORTIZ, A.: Sociedad y Estado en el siglo XVIII español. Barcelona, 1976, y Las clases privilegiadas en el Antiguo Régimen. Madrid, 1979. SANZ AYÁN, C.: Los banqueros de Carlos II. Valladolid, 1989, MARTínez Millán, J.: (Ed.) Instituciones y elites de poder en la Monarquía Hispana durante el siglo XVI. Madrid, 1992. MOLAS RuBALTA, P.: La burguesía mercantil en la España del Antiguo Régimen. Madrid, 1985. y ENCISO RECIO, L. M. (Coord): La burquesía española en la Edad Moderna. Valladolid, 1996, entre otros.

2 FAYARD, J.: Los miembros del Consejo de Castilla (1621-1746). Madrid, 1882 y «Los ministros del Consejo Real de Castilla (1746-1788), Cuadernos de Investigación Histórica, $\mathrm{N}^{\circ}$ 6, págs 109-136. Sobre los intendentes ABBAD, F y OZANAM, D. Les intendants espagnols du XVIIIème siécle. Madrid, 1992; sobre los militares ANDÚJAR CASTILLO, F. Los militares en la España del XVIII. Un estudio social. Granada, 1991 y BALDUQUE MARCOS, L.M.: El Ejército de Carlos III. Extracción social, origen geográfico y formas de vida de los oficiales de S.M. Tesis doctoral inédita. Universidad Complutense de Madrid, octubre de 1993.

3 Guerrero MAYLlo, A.: Familia y vida cotidiana de una elite de poder. Los regidores madrileños en tiempos de Felipe II. Madrid, 1993. HERNÁNDEZ, M.: « Reproducción y renovación de una oligarquía urbana: los regidores de Madrid en el siglo XVIII", en Anuario de Historia del Derecho Español, núm.LVI, págs 637-681. Y A la sombra de la Corona. Poder local y oligarquía urbana (Madrid, 16061808). Madrid, 1995.

4 ARANDA PÉReZ, F.J.: Poder municipal y oligarquías urbanas en Toledo en el siglo XVII, 2 tomos. Madrid, 1992.

5 Guillamón Alvarez, J.: Regidores de la ciudad de Murcia (1750-1836). Murcia, 1989.

6 MARINA BARBA, J.: Poder municipal y reforma en Granada durante el siglo XVIII. Granada, 1992.

7 TORRAS I RIBÉ, J.M. Els municipis catalans de l'Antic Règim (1453-1808). Procediments electorals, òrgans de poder y grups dominants. Barcelona, 1983.

8 Gimeno SANFeLIU, M. J. La oligarquía urbana de Castelló en el siglo XVIII. Castellón. 1990. IRLÉS VICENTE, M ${ }^{\text {a }}$ C.: Al servicio de los Borbones. Los regidores valencianos en el siglo XVIII.Valencia, 1996. 
riqueza personal, descubrir cual es el papel y los intereses de clase del funcionariado, de los servidores burocráticos de la Monarquía y de las elites y grupos medios urbanos de las grandes ciudades, - miembros al fin y al cabo del aparato estatal en sus distintos niveles-, supone conocer su naturaleza social y entender mejor la composición del Estado Moderno español.

Valga como ejemplo el de oligarquía municipal de la depauperada y poco poblada ciudad de Gaudalajara del siglo $\mathrm{XVIII}^{9}$, pero cuya elite tuvo un importante papel activo al servicio de la Corona tanto porque al ser ciudad con voto en Cortes ${ }^{10}$ de su corparación municipal podían salir diputados del Reino, o de la Diputación del Servicio de Millones vinculada a Hacienda y por lo tanto consejeros $^{11}$, como en las espectativas de ascenso social y profesional en la muy próxima Villa y Corte que actuaba como polo de atracción de este grupo urbano. Es el objetivo de este artículo.

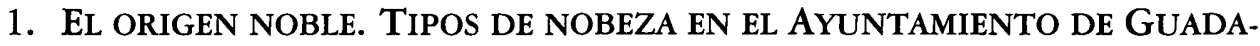 LAJARA.}

Por acuerdo municipal de 3 de junio de 1647 los capitulares del Concejo de Guadalajara, reunidos en cabildo, decidieron exigir en adelante a los nuevos regidores la condición nobiliaria y la limpieza de sangre ${ }^{12}$. Se unía así a buen número de Ayuntamientos como Toledo, Sevilla, Córdoba o Madrid ${ }^{13}$ que, a lo largo de los siglos XVI y XVII, decidieron ennoblecer a sus oligarquías municipales y cortar el ascenso a grupos burgueses que quisieran lavar sus orígenes con el prestigio social y el poder que daba la propiedad de un oficio municipal.

9 Según el Vecindario de 1717 tenía 450 vecinos (unos 2.250 habitantes), el Catastro de Ensenada de 1751 nos da la cifra de 1.300 (unos 5.130 habitantes), el Censo de Aranda del 68 unos 5.100 habitantes y el de Floridablanca de 1786 unos 6.740 habitantes. Como vemos una ciudad muy poco poblada para ser cabeza de provincia-intendencia con voto en Cortes. SALGADO OLMEDA, F.: "La ciudad de Guadalajara a mediados del siglo XVIII, (1746-1766)", en Wad-al-Hayara, $n^{\circ} 24$. Guadalajara, 1977, págs 67-111.

${ }^{10}$ Es desde 1435 cuando Guadalajara queda definitivamente fijada como una de las 17 ciudades cabecera de provincia con representación en Cortes de Castilla (después de 1492 se añadió Granada). CARretero Zamora, J.M.: Cortes, monarquía, ciudades. Las Cortes de Castilla a comienzos de la época moderna (1476-1515). Madrid, 1988, pág. 4.

11 Sobre la Cortes de Castilla y la Diputación véase CaStellano, J.L.: Las Cortes de Castilla y su Diputación (1621-1789). Entre pactismo y absolutismo. Madrid, 1990.

12 Visto en A.M.GU. Libro de Acuerdos de 1709.

13 Para Toledo véase ARANDa PÉRez, F.J. Op. Cit. Sobre Sevilla y Córdoba Domínguez ORTIZ, A.: Las clases privilegiadas en el Antiguo Régimen. Madrid, 1973, pág. 127 y Sociedad y Estado en el siglo XVIII español. Madrid, 1984, pág.459, y para Madrid HeRnáNDEZ BeníTEZ, M.: «El cierre de las oligarquías urbanas en la Castilla Moderna: el estatuto del Concejo de Madrid (1603)», en Revista Internacional de Sociología. N 45, 1, Madrid, 1987, págs 179-198. 
Siguió con la pretensión, ya en el siglo XVIII, de conseguir Estatuto de «nobleza de sangre» que lustraba aún más, si cabe, a sus capitulares, y Guadalajara - como otras muchas ciudades- lo intentó entre 1752 y 1756, aunque los exiguos recursos municipales de donde saldría el dinero - público- para pagar un galardón - privado - a añadir a los méritos de los regidores, no permitieron tal «privilegio» a la Ciudad ${ }^{14}$.

Así pues, en principio, se podría afirmar que todos los regidores de la ciudad de Guadalajara en siglo XVIII eran nobles. Pero, ¿a qué tipo de nobleza pertenecía la elite de poder municipal? ${ }^{15}$.

El siguiente cuadro resume las diferentes categorías nobiliarias de la oligarquía municipal en Guadalajara entre 1718-1800, en que ejercieron o poseyeron el regimiento 115 regidores.

TIPOS DE NOBLEZA ENTRE LOS REGIDORES DE GUADALAJARA

$(1718-1800)$

\begin{tabular}{lcccccc}
\hline & Títulos & $\begin{array}{c}\text { Caballeros } \\
\text { DE Ordenes }\end{array}$ & $\begin{array}{c}\text { Señores De } \\
\text { VASAllos }\end{array}$ & Hidalgos & Sin Def. & Total \\
\hline $\begin{array}{l}\text { Títulos } \\
\text { Títulos } \\
+ \text { Cab. Orden }\end{array}$ & 1 & - & - & - & - & 1 \\
$\begin{array}{l}\text { Títulos + } \\
\text { Señores v. }\end{array}$ & 7 & 2 & - & - & - & 4 \\
Títulos + & & - & 6 & - & - & 13 \\
Cab. Orden + & & & & & & \\
Señores & 8 & 8 & 8 & - & - & 24 \\
Cab. Orden & - & 13 & - & - & - & 13 \\
Señor de v. & - & - & 1 & 1 & - & 2 \\
Hidalgos & - & - & 1 & 47 & - & 48 \\
Sin definir & - & - & - & - & 10 & 10 \\
\hline TOTAL & 18 & 23 & 16 & 48 & 10 & 115 \\
\hline
\end{tabular}

${ }_{14}$ Ante la información del regidor comisionado para esta gestión los regidores contestaron «respecto que al presente se balla esta Ciudad escasa de caudales ... acordó asimismo que por abora se cese en ella». SALGADO OlmeDA, F.: «Sobre la condición nobiliaria del Ayuntamiento de Guadalajara en el siglo XVIII: la cuestión del Estatuto de nobleza de sangre para la Ciudad en 1752», Actas del IV Encuentro de Historiadores del Valle del Henares. Alcalá de Henares, noviembre de 1994, págs 227 a 333.

15 Sobre las categorías nobiliarias en el Antiguo Régimen véase el clásico libro de DomínGUEZ ORTIZ, A.: Las clases privilegiadas en el Antiguo Régimen. Madrid, 1973, págs 1 a 197.

Hispania, LXII/2, núm. 211 (2002) 693-746 


\section{Los TítULOS}

Dieciocho regidores de Guadalajara entre 1718 y 1800 fueron nobles titulados (casi un $16 \%$ del total) y 10 de ellos fueron, además, caballeros de alguna Orden Militar. La mayoría de ellos de reciente creación.

El título más antiguo que encontramos entre ellos es el de Marqués de Villatoya, concedido inicialmente el 18 de febrero de 1686 a D. Juan Francisco Pacheco y Duque de Estrada ${ }^{16}$, regidor de Guadalajara y que heredaron sus sobrinos D. Luis de Arellano y Pacheco y D. Alonso de Arellano en la primera mitad el siglo XVIII; y el más reciente, el de Conde de Saceda, fue concedido a D. Juan Francisco de Goyeneche el 17 de diciembre de $1743^{17}$.

Entre ellos no hubo ningún Duque ni Grande de España ${ }^{18}$ y encontramos 12 Marqueses $^{19}, 4$ Condes y un Vizconde. Tampoco eran nobleza antigua; todos los títulos fueron creados en el reinado del último Habsburgo español (que concedió cuatro de los títulos que luego poseyeron los regidores de Guadalaja$\mathrm{ra}^{20}$ ) y en el del primer Borbón (que creó seis ${ }^{21}$ ). El Archiduque D. Carlos de Austria concedió dos a una misma persona: D. José Antonio de Torres Morales $^{22}$. Tampoco sus rentas eran excesivamente altas, 53.500 reales rentaban en 1769 los mayorazgos del Marqués de Peñaflorida ${ }^{23}$, unos 44.000 reales líquidos rentaban los del Conde de la Vega del Pozo ${ }^{24}, 75.359$ reales y 27 maravedís limpios rentaban los del Vizconde de Irueste en 1763, descontadas las cargas ${ }^{25}$; 136.102 reales los del Marqués de Villatoya ${ }^{26}$, los del Marqués de Andía y de la Ribera rentaban 301.748 reales y 21 maravedís en $1788^{27}$, aunque destacan los Orcasitas, condes de Moriana, ${ }^{28}$ los Iriberri, Marqueses de Valbueno ${ }^{29}$ y los

\footnotetext{
${ }^{16}$ Elenco de Grandezas y Títulos nobiliarios... Edición de 1976, pág. 614. Existe una más reciente edición de 1997 a cargo de A. ALONSO DE CADENAS Y LÓPEZ, y V. DE CADENAS Y ViCENT.

17 Caro Baroja, J. La bora navarra del siglo XVIII. Pamplona, 1969, pág. 84

${ }_{18} \mathrm{Si}$ exceptuamos a los Duques del Infantado, que no consideramos regidores al ejercerse sus siete regimientos por tenientes.

${ }_{19}$ Uno de los Marqueses, el de Villamejor era además Príncipe de las Torres, título italiano concedido por el Archiduque D. Carlos de Austria, pero desde 1724 no se usó.

${ }^{20}$ Son los Marquesados de Villatoya, en 1686; el de la Ribera, en 1690; el de Andía, en 1695 y el Condado de Moriana en 1698.

${ }^{21}$ El de Conde de la Vega del Pozo, en 1705 y Conde de Saceda en 1743; los Marquesados de Peñaflorida, en 1709; de Belzunce, en 1731; de Valbueno (o Balbueno) en 1732 y de Ugena, en 1735.

${ }^{22}$ El de Marqués de Villamejor y Vizconde de Irueste, en 1718, ambos títulos permanecieron en la misma familia, los Torres.

23 A.H.P.M. Protocolo 16.180 , fols 257 r y ss.

${ }^{24}$ A.H.P.M. Protocolo 15.494, fols $186 \mathrm{r}-193$ v.

25 A.H.P.GU. Protocolo 842, fols 1-44 r.

${ }^{26}$ SAltillo, MARQUÉs DE: Historia nobiliaria española. 2 tomos. Madrid, 1951, pág. 334.

27 A.H.N. Consejos. Legajo 5.251-2.

${ }^{28}$ En 3.095.735 reales se evaluó la fortuna inventariada del primer Conde de Moriana y en 1.039.236 la de su hijo. A.H.P.M. Protocolo 15.766.
} 
Goyeneche, Condes de Saceda, Marqueses de Belzunce y de Ugena a finales de siglo $^{30}$, pero no eran comparables a las de las grandes casas nobiliarias ${ }^{31}$.

Según Domínguez Ortiz ${ }^{32}$, el acceso al escalafón más alto de la condición nobiliaria - conseguir un título nobiliario- encontró a lo largo de todo el Antiguo Régimen español un buen aliado en la Monarquía y si en 1520 había 20 Grandes y 35 títulos de Castilla a finales del reinado de Felipe II eran cerca de 100; Felipe III y Felipe IV crearon unos 45 el primero y unos 92 el segundo, respectivamente; aunque fue el hijo de éste último el que creó tantos títulos como en los dos siglos anteriores. El reinado de Carlos II se caracterizó por la concesión indiscriminada de títulos calculando que, entre vitalicios y hereditarios fueron $221^{33}$, unas veces por servicios prestados - administrativos, militares o económicos - y otras a quien pudiera comprarlos, a veces por precios no excesivamente altos —entre 200.000 y 300.000 reales-; muchos de ellos habían sido concedidos a hombres de negocios y asentistas que apoyaron decisivamente a la Monarquía en los momentos decisivos de crisis financiera, en concepto de merced por sus empréstitos y asientos, cuyo pago no podía asumir la Real Hacienda ${ }^{34}$.

También Felipe V concedió buen número de títulos (unos 200 en los 45 años que reinó) pero en este caso, premiando fundamentalmente la afección a la causa borbónica, reconociendo, incluso, los creados por el Archiduque D. Carlos según las estipulaciones del Tratado de Viena-35. Es el caso de varios de los títulos que a continuación veremos, concedidos en general a asentistas o altos burócratas de los Consejos, especialmente del de Hacienda, como Tesoreros y administradores de rentas reales y algunos de ellos eran regidores de Guadalajara.

\footnotetext{
${ }^{29} \mathrm{La}$ fortuna del primer Marqués de Valbueno hemos calculado que ascendía a 1.980 .000 reales a su muerte A.H.P.M. Protocolo 16.706. La de su hijo D. Antonio de Iriberri a 1.616 .931 reales. A.H.P.M. Protocolo 18.015.

${ }^{30}$ Sólo el mayorazgo de Saceda rentaba en 1772194.564 reales y 32 maravedís. A.H.P.M. Protocolo 16.077, fol. 654 r, pero heredó el de su primo D. Jan Francisco de Goyeneche, Marqués de Ugena, tasado en unos 9 millones de reales, aunque sin conocer su renta.

31 Por ejemplo las rentas anuales del Duque de Alba ascendían a unos 9.166 .000 reales de vellón, las del Infantado ascendían a unos 250.000 ducados (unos 2.750 .000 reales) y el Ducado de Villahermosa a unos 2.000.000 de reales. MORALES MOYA. A.: Poder político, economía e ideología en el siglo XVIII español: la posición de la nobleza. Madrid, 1993, 2 vol., págs 1.039 y 1.040 . El Conde de Aranda tenía 1.600.000 reales de renta anual. DESDESVISES DU DESERT, G.: La España del Antiguo Régimen. Madrid, 1989, pág. 147, y la Casa de Osuna cerca de 1.000.000 de reales según ATIENZA HERnÁndeZ, I.: Aristocracia, poder y riqueza en la España moderna. La Casa de Osuna, siglos XV-XIX. Madrid, pág. 343.

32 Domínguez Ortiz, A.: Las clases privilegiadas ... Op. Cit. Págs 71 a 85.

33 Ibidem, pág. 75 y 76

34 Véase de SANZ AYÁN, C.: Los Banqueros de Carlos II. Valladolid, 1989.

35 Domínguez Ortiz, A.: Sociedad y Estado.... Op. Cit. Pág. 349.
} 
Cabría, pues, definir a la nobleza titulada propietaria de regimientos de Guadalajara como una nobleza burocrática, asociada a la administración de la Hacienda Real y al servicio de la Monarquía borbónica. Estudiemos los diferentes títulos:

El título de Marqués de la Ribera había sido concedido por Carlos II a D. Luis de Zúñiga y Guzmán, regidor de Guadalajara, caballero de Santiago y geltilhombre del rey Carlos II el 30 de agosto de $1690^{36}$. El título fue dado a cambio de una concesión, de una renta fija anual de 1.000 pesos (20.000 reales de vellón) situada sobre los beneficios de una encomienda en Yucatán; la concesión fue dada por el rey, desde 1674, a cambio de servicios prestados y por el tiempo de «dos vidas». Pero la concesión no tuvo efecto y en 1692, el hijo y primer heredero de D. Luis, D. Juan de Zúñiga renunció a los pesos - que por otro lado no cobraba puntualmente- a cambio del título hereditario, que poseía su padre de forma vitalicia ${ }^{37}$. A su muerte, el título lo heredó el II Marqués de la Ribera, D. Domingo de Zúñiga Guzmán y Tovar, Caballero de Santiago, del Consejo de Hacienda y Alférez mayor de Guadalajara entre 1710 y 1719 (era hijo segundo de D. Luis), no sin haber renunciado antes a sus derechos D. Teresa de Zúñiga, monja carmelita, única hija del primogénito, D. Juan, en 171138. El carácter de servicio a la Monarquía de toda la familia Zúñiga nos lo confirman sus oficios, bien en palacio como D. Luis, bien en el Consejo de Hacienda como D. Domingo o el de un tercer hermano D. Diego de Zúñiga, asimismo Caballero de Santiago y consejero de Indias, soltero ${ }^{39}$. El marquesado fue heredado a la muerte de $\mathrm{D}$. Domingo por su hija $\mathrm{D}^{\mathrm{a}}$ María Teresa de Zúñiga y Tovar, que lo aportó a su marido D. Juan Francisco Remírez de Baquedano, caballero de Santiago ${ }^{40}$, sucesor también en el oficio de Alférez mayor por nombramiento de la Casa del Infantado y que heredará también el título navarro de Marqués de Andía por muerte de su tío, D. Juan Remírez (o Ramírez) de Baquedano.

Los Remírez de Baquedano, de origen navarro, fueron otra familia que, instalada en la Corte a fines del siglo XVII, sirvió a la Corona en la alta administración de los Consejos. El Marquesado de Andía, título navarro, lo recibió D. Diego Remírez de Baquedano, abuelo del Alférez mayor D. Juan Francisco, el 20 de febrero de 1695, cancelando el de Vizconde de Zudaire ${ }^{41}$. En este caso el

\footnotetext{
36 Elenco de Grandezas..., pág. 938.

37 A.H.P.GU. Protocolo 4.076/16. S/f, 5 de marzo de 1692.

38 A.H.P.GU. Protocolo 839, 28 de marzo de 1711.

39 Asimismo hay un completo informe de los méritos y servicios de la familia en A.H.N. Consejos. Legajo 5.251 , exp. 5 . fols $50 \mathrm{v}$ a 52 vto.

${ }^{40}$ Hábito concedido en 1711. VignaU V. y Uhagon, F.R. Indice de pruebas de Caballeros que ban vestido el hábito de Calatrava, Alcántara y Montesa, desde el siglo XVI hasta la fecha. Madrid, 1903. Pág 141. Es el expediente 2.177 de la sección de Ordenes del A.H.N.

41 Aunque inicialmente, en 1680, había recibido el de Marqués de San Martín de Amescoa.. El Valle de Amescoa, del que tenía la jurisdicción, se opuso ofreciendo 4.000 reales de a ocho, (de cuño
} 
marquesado fue concedido a cambio de servicios militares, ya que $D$. Diego había servido en 1636 y en 1638 a la Corona, levantando a su costa sendas compañías de infantería de 200 hombres en las guerras contra Francia. El padre de D. Juan Francisco fue Teniente General de Artillería y sus tíos fueron Consejeros de Castilla y de Indias respectivamente ${ }^{42}$.

Perteneciente al mismo grupo familiar ${ }^{43}$ de los Ribera y Andía fue el también regidor y Alférez mayor D. Francisco Javier de Dicastillo, caballero de Santiago ${ }^{44}$ y Conde de la Vega del Pozo. Tenemos noticias de los López de Dicastillo por los trabajos de Janine Fayard y de Mauro Hernández ${ }^{45}$. El padre de D. Francisco Javier, Don Mateo, fue consejero de Castilla, y recibió el título navarro de Conde de la Vega del Pozo el 25 de abril de $1705^{46}$ y su madre Doña Catalina Méndez Testa provenía de una familia muy vinculada al Ayuntamiento de Madrid desde mediados del siglo XVII, por lo que su marido y dos de sus hijos fueron regidores de Madrid ${ }^{47}$.

Los Baquedano y los Dicastillo no fueron los únicos navarros, -cuyo desembarco en Madrid desde finales del siglo XVII ha descrito tan bien Caro Baroja ${ }^{48}$ - con intereses en Guadalajara en el siglo XVIII; destacan los dos hijos del poderoso asentista, tesorero y hombre de negocios con Carlos II y Felipe V, D. Juan de Goyeneche, que compraron sendos regimientos en 1722 y 1740 . Ambos accedieron a la nobleza titulada en este caso por los servicos prestados por su padre, fundamental pilar económico de Felipe V en la Guerra de Sucesión española. Su figura ha sido estudiada por Caro Baroja ${ }^{49}$, quien destaca su

antiguo $=272 \mathrm{mrs}$ ); cambiada la jurisdicción por los montes de Andía y Urbasa recibió el título de Marqués de Andía. A.H.N. Consejos, legajo 5.252, expte 5. fols 26 r a 29 r. Véase asimismo el práctico Catálogo alfabético de los documentos referentes a Títulos del Reino y Grandezas de España. Conservados en la Sección de Consejos suprimidos. Tomo III. Madrid, 1953, pág. 16.

42 D. Juan Remírez de Baquedano, Caballero de Santiago, Alcalde de Casa y Corte, II Marqués de dicho título y $\mathrm{D}$. Gonzalo Remírez de Baquedano, caballero de Santiago, Fiscal de la Audiencia de Chile y Consejero de Indias. Un tercer tío fue colegial en el Colegio de Santa Cruz de Valladolid, todos solteros. Ibidem.

${ }^{43}$ Estaba casado con Doña Josefa Solís de Magaña y Molina, sobrina y prima respectivamente del los anteriores Alféreces, Marqueses de la Ribera y de Andía.

${ }^{44}$ CADENAS Y VICENT, V.: Caballeros de la Orden de Santiago. Siglo XVIII. Madrid, 1977, tomo II, pág. 78

${ }^{45}$ Fayard, J.: Los miembros del Consejo de Castilla... Op. Cit. Págs 68, 102, 164, 212, 343 y 511 y Hernández Benítez, M. A la sombra de la Corona... Op. Cit. Págs. 127, 169, 187, y un espléndido cuadro genealógico de la familia en las págs. 368 y 369.

${ }^{46}$ Cancelando el previo de Vizconde de Jorbalán. Catálogo alfabético de los documentos referentes a Títulos... Op. Cit. Tomo I, año 1951, pág. 599, Hernández Benítez, M. A la sombra de la corona... pág. 87.

47 D. Agustín y D. Felipe. Sobre los Méndez Testa en ibidem, págs 47 y 169.

48 Caro Baroja, J.: La hora navarra ... Op. Cit., págs 81-223.

49 Ibidem, págs. 81-195 especialmente. Véanse asimismo los artículos de BenITO APARICIO, Fc ${ }^{\circ}$ J. y BlasCO EsQuivias, B.: «El Nuevo Baztán: Avance para un estudio» en I Jornadas de Estu- 
meteórico ascenso como banquero y asentista con Carlos II y su segunda mujer Mariana de Neoburgo, su cargo de Tesorero de milicias, su actividad como abastecedor monopolístico del Ejército y de la Marina y director y propietario del primer periódico, la «Gazeta de Madrid», desde 1697. Con Felipe V, volvió a tener la confianza económica de importantes personajes de la Corte, siendo tesorero de sus mujeres $\mathbf{M}^{a}$ Luisa de Saboya e Isabel de Farnesio, y transmitiendo el cargo a sus hijos ${ }^{50}$.

Su primer hijo fue D. Francisco Javier de Goyeneche y Balanza nacido en $1690^{51}$. Fruto de la mentalidad de la época pronto empieza a adosar a su poder económico un brillante expediente aristocrático: hidalgo de sangre al provenir del valle de Baztán, en Navarra ${ }^{52}$, en 1701 consigue entrar en la Orden de Santiago ${ }^{53}$, en 1707 heredó de su padre la Tesorería del Consejo de Indias ${ }^{54}$ y en 1722 compró en 10.000 reales de vellón el oficio de regidor de Guadalajara con el título honorífico de Alcalde Mayor ${ }^{55}$; su padre era señor de Belzunce en $\mathrm{Na}$ varra, y de Illana, Saceda de Trasierra, la Olmeda de la Cebolla y Nuevo Baztán en las provincias de Cuenca y Toledo ${ }^{56}$ y D. Francisco Javier, el 13 de mayo de 1731 recibió título navarro de Marqués de Belzunce ${ }^{57}$. Dedicado a sus empresas económicas, y pasando largas temporadas en su palacio de Nuevo Baztán murió, sin sucesión, en $1748^{58}$, pasando todos su biene a su hermano, D. Francisco Miguel, también regidor de Guadalajara.

La trayectoria de éste último, D. Francisco Miguel, fue parecida. Nacido en $1705^{59}$, había heredado también de su padre el espíritu dinámico y empresarial; rápidamente adquiere un hábito de Santiago, ya que el expediente se empieza en $1728^{60}$. En 1735 muere su padre y desde entonces será Tesorero General de la reina Isabel de Farnesio. En 1740, con ocasión de su matrimonio con $\mathrm{M}^{\mathrm{a}}$ Antonia de Indáburu, se le volvió a pedir probanza en la Orden de San-

dios sobre la provincia de Madrid. Madrid, 1980,. y «Nuevo Baztán y el prereformismo borbónico», en A.I.E.M. Tomo XVIII, 1981, págs 287-298.

so Ibidem, pág. 90 y 101 a 109.

${ }^{51}$ Ibidem. Pág. 106.

52 Poseían todos los habitantes de este valle la hidalguía desde 1440, cuya Ejecutoria de nobleza su padre publicó en 1685. Ejecutoria, Antigüedad y Blasones del Valle de Baztán que dedica a sus bijos $y$ originarios Juan de Goyeneche.

${ }_{53}$ A.H.N. Sección de Ordenes militares. Indice de expedientillos y datos de bábito de Caballeros en Santiago, Calatrava y Montesa. Madrid, 1976. Legajo $61 \mathrm{n}^{\circ} 6215$.

54 A.H.N. Consejos. Libro 733.

55 A.M.GU. Libro de Acuerdos de 1722. Título de regidor presentado por D. F. Javier de Goyeneche el 2 de mayo de 1722

56 Caro Baroja, J.: Op. Cit. Pág. 118.

57 Ibidem. Pág. 124 y A.H.N. Consejos. Legajo 8.977.

58 Caro Baroja. J.: Op. Cit. Pág. 183.

59 Ibidem. Pág. 107.

60 Ibidem. Pág. 133. 
tiago ${ }^{61}$; precisamente ese año también compró el regimiento de Guadalajara ${ }^{62}$. El 17 de diciembre de 1743 recibió el título nobiliario de Conde de Saceda en Navarra, cancelando el previo de Vizconde de Huerta, para sí y sus sucesores ${ }^{63}$. Cortesano, gentilhombre de Cámara de Felipe V, en 1748, por muerte de su hermano recibió el mayorazgo fundado por su padre en cabeza del anterior ${ }^{64}$, añadiendo al condado de Saceda el marquesado de Belzunce y los dos títulos de regidor de Guadalajara. Mayordomo de Isabel de Farnesio y su Tesorero, murió en $1762^{65}$. Su hijo fue D. Juan Javier de Goyeneche e Indáburu ${ }^{66}$ que tomó posesión del regimiento de Guadalajara en 1770 y que a los dos títulos de Belzunce y Saceda añadió el de Marqués de Ugena, que concedió Felipe V el 13 de marzo de 1731 a D. Juan Francisco de Goyeneche, sobrino de D. Juan de Goyeneche y primo de los primeros Belzunce y Saceda ${ }^{67}$, y cuya rama principal se extingió.

El caso de los Goyeneche es un ejemplo típico de nobleza nueva de origen burgués en la que su padre, un pequeño hidalgo de espíritu empresarial, aprovechando influencias y solidaridades regionales ${ }^{68}$, va escalando posiciones y deja un inmenso patrimonio industrial y económico a sus hijos, que continúan estas actividades, pero no ajenos al espíritu nobiliario de la época, siguen el triple proceso de compra de señoríos ${ }^{69}$, adquisición de hábito de una Orden Militar y consecución de un título nobiliario: todo un ejemplo de ascenso social a partir del préstamo a la Monarquía. «Poderoso caballero...»

Primos segundos de los anteriores fueron los también regidores de Guadalajara D. Tomás de Iriberri y Goyeneche y su hijo D. Antonio de Iriberri y Lastiri, Marqueses de Valbueno. D. Tomás de Iriberri Goyeneche, primer Marqués

\footnotetext{
61 Expediente 10.192. Citado por COUTO DE LEÓN, M ${ }^{\mathrm{a}}$.D.: Pruebas para contraer matrimonios con Caballeros de la Orden de Santiago. Madrid. 1976.

62 A.H.N. Consejos. Libro 624, folio 56 recto.

${ }_{63} \mathrm{Ibidem}$. Folio $242 \mathrm{v}$. El vizcondado era un paso previo a la consecución de los títulos de Conde, Marqués o Duque, anulándose al recibir estos títulos de mayor consideración nobiliaria.

${ }^{64}$ Poseía otro fundado el mismo día.

65 Falleció el 3 de octubre de 1762. Poder para testar en A.H.P.M. Protocolo 19.348, fol. 930 r$934 \mathrm{r}$.

${ }^{66}$ Falleció en 1788. A.H.P.M. Protocolo 20.380, fol. 23-50 r. Memoria testamentaria de 11 de octubre de 1785.

67 Elenco de Grandezas ...Pág. 551. Sobre la personalidad de este otro gran asentista, D. Juan Francisco de Goyeneche véase CARo BAROJA, J.: Op. Cit. págs 195 a 219.

68 Ambos hermanos fueron miembros de la Cofradía de San Fermín de los Navarros, de la que en 1734, Francisco Javier fue elegido presidente, y en 1739 su hermano. Ibidem. Pág. 185.

${ }^{69} \mathrm{Ibidem}$. Pág. 141-152; Caro Baroja señala que en la compra de señoríos por Goyeneche había una mentalidad más empresarial que nobiliaria. Efectivamente en todos los pueblos o lugares que compró fomentó y creó «a la manera colbertiana» y por iniciativa privada industrias de paños o de cristal. Nuevo Baztán fue levantado por Churriguera entre 1709 y 1713 y además de la iglesia y de su palacio cuenta con edificios dedicados a fábrica, almacenes, pósitos, amén de las casas para los obreros. Otras manufacturas fueron establecidas en la Olmeda de la Cebolla (hoy de la Sierra). En Illana, comprada al Marqués de Almonacid instaló industrias de tejidos y curtidos, y dónde aún hoy en día puede admirarse el palacio barroco de los Goyeneche.
} 
de Valbueno, era hijo de Andrés de Iriberri y Catalina de Goyeneche, hermana del fundador de Nuevo Baztán ${ }^{70}$; caballero de Santiago desde $1716^{71}$, Tesorero mayor de Felipe V y consejero de Hacienda, el 20 de febrero de 1732 recibió, posiblemente por compra, el marquesado de Valbueno ${ }^{72}$ - pueblo próximo a Guadalajara cuyo señorío había comprado en $1726^{73}$ - cancelando el previo de Vizconde de San Antonio ${ }^{74}$; antes, en 1730, había comprado el regimiento ${ }^{75}$. Su hijo, D. Antonio de Iriberri y Lastiri, paje de Felipe V, inició su expediente de caballero de Santiago en mayo de $1729^{76}$, solicitó el cargo palaciego de Mayordomo de semana de la Reina en $1733^{77}$, y en 1743 aparece como Caballerizo de campo del Rey y consejero de Hacienda ${ }^{78}$. El expediente en la Orden de Santiago para casarse con Doña Teresa $\mathrm{O}^{\prime}$ Brien $\mathrm{O}^{\prime}$ Connor se inició en $1737^{79}$. A la muerte de su padre, en 1740 , recibió en herencia el título nobiliario. Huelga decir, que también en este caso, las influencias familiares, geográficas, económicas y burocráticas posibilitaron el ascenso social de la familia de nuestro regidor.

De origen vasco, pero también con antecedentes asentistas en su familia ${ }^{80}$ fueron los regidores D. Juan de Orcasitas y Avellaneda, y su hijo D. Juan Francisco de Orcasitas y Oleaga, ambos caballeros de Alcántara ${ }^{81}$ y Condes de Moriana, al servicio de la Monarquía en la alta administración: D. Juan de Orcasitas (padre) fue Alguacil mayor del Consejo de Ordenes y Tesorero del Con-

70 Ibidem. Pág. 192

71 A.H.N. Sección de Ordenes Militares. Indice de expedientillos y datos de bábito... Pág. 280. Legajo 67. Expte $n^{\circ} 6746$

${ }_{72}$ El título fue tasado a su muerte en 176.000 reales de vellón. A.H.P.M. Protocolo 18.085.

73 A.H.P.M. Protocolo 14.642, fol. 84-168 r.

${ }^{74}$ Catálogo alfabético de los documentos referentes a Títulos... Op. Cit. Tomo II, pág. 179. A.H.N. Consejos: Legajo 8.977. Expte. $n^{\circ}$ 755. También en Caro Baroja, J.: Op. Cit. Pág. 192.

75 A.M.GU. Libro de Acuerdos de 1731. Titulo fecha de 11 de abril de 1731.

${ }^{76}$ A.H.N. Sección de Ordenes Militares. Indice de expedientillos... Op.Cit. Pág. 280. Legajo 69, expte $\mathrm{n}^{\circ} 6925$.

77 A.G.P Caja 694-3. "D. Antonio de Iriberri Cavallero del Orden de Santiago a los pies de V.M. Dize que ha mas de siete años que sirve a V.M. de Page (sic) de su Real Persona y hallándose en edad suficientre para obtener empleo en que continuar su mérito, y práctico en los idiomas de francés e italiano por aver estado algunos años en Franzia Roma y otras partes; en esta atención y a los dilatados méritos de su Padre el Marqués de Valbueno que ha mas de veinte años sirve a V.M. en diversos empleos y actualmente en el (de) Thesorero General. Suplica a V.M. se sirva onrrar (sic) al suplicante con los honores de Mayordomo de Semana de la Reyna nra Señora...."

${ }_{78}$ A.H.P.M. Protocolo 16.709, fol. 98 a 101. Poder para testar de 27 de febrero de 1743.

79 Couto de LeÓn, Mª : D. Op. Cit. Expediente 10.316.

80 Sobre los asientos de D. Francisco de Orcasitas, hermano del regidor D. Juan de Orcasitas véase SANZ AYÁn, C.: Op. Cit, págs 423 a 425 y Bravo LOZANO, J.: «D. Francisco de Horcasitas. Las posibilidades de Madrid a fines del siglo XVII», en Estudios de Historia Social, n 36-37, enerojunio de 1986, págs 497-521. Igualmente el testamento de 3 de septiembre de 1672 en A.H.P.M. Protocolo $10.415, \mathrm{~s} / \mathrm{f}$.

${ }^{81}$ El hábito lo recibieron en 1680 y 1694 respectivamente. VIGNAU, V y UHAGON, F.: Indice de pruebas de Calatrava, Alcántara y Montesa. Op. Cit., pág 242. Son los expedientes 728 y 730 de la Sección de Ordenes del A.H.N. 
sejo de Hacienda, al igual que su hijo, Tesorero de Guerra. El título nobiliario de Castilla se concedió el 17 de marzo de 1698 a D. Juan de Orcasitas Avellaneda, cancelando el Vizcondado previo de Moriana del Río ${ }^{82}$.

Los títulos de Príncipe de las Torres, Marqués de Villamejor y Vizconde de Irueste fueron creados por el pretendiente austríaco al trono español D. Carlos de Habsburgo el año de $1718^{83}$ en la persona del regidor D. José de Torres Messía y Morales, que apoyó su bando en la guerra de Sucesión. Cuando por el Tratado de Viena se amnistió a todos los partidarios austracistas, reintegrándoles sus bienes, oficios y mayorazgos, Felipe $\mathrm{V}$ reconoció los títulos creados por el austríaco, entre ellos los de Torres; en 1726 solicitó al Rey recibir los títulos «que el Emperador le bizo merced» de Marqués de Villamejor y Vizconde de Irueste para los primogénitos ${ }^{84}$, olvidando definitivamente el de Príncipe de las Torres, que no se volvió a utilizar. Poseyeron el regimiento en el periodo estudiado su hijo, D. Manuel María de Torres y Dávalos, Vizconde de Irueste, su nieto D. José Zósimas de Torres Heredia, II Marqués de Villamejor y su biznieto D. José de Torres y de la Cueva, III Marqués.

Finalmente el último de los títulos nobiliarios presentes en el regimiento de Guadalajara en el siglo XVIII fue el de Marqués de Peñaflorida, que poseyó D. Juan Cristóbal Justiniani y Arellano, regidor desde 1768 a 1799. El título nobiliario fue concedido el 9 de abril de 1709 a su abuelo D. Justiniano Justiniani Marcelli, Alguacil Mayor del Consejo de Italia ${ }^{85}$.

Todos los títulos nobiliarios de Castilla, entre ellos los de los regidores de Guadalajara, debían pagar a la Corona tras su concesión o trasmisión, la media anata $^{86}$, al igual que cualquier oficio venal, y además las «lanzas», impuesto creado por Carlos V, que en el siglo XVIII ascendía a 3.600 reales anuales por cada título nobiliario (Conde, Duque, o Marqués) que se poseyese ${ }^{87}$, más otros 3.600 en el caso de recibir la Grandeza (es decir 7.200 reales) ${ }^{88}$. Sin embargo, los títulos navarros estaban exentos del pago de lanzas y anatas ${ }^{89}$.

\footnotetext{
82 Elenco de Grandezas y Títulos nobiliarios... Op. Cit. Pág. 573.

83 Elenco de Grandezas .... (Edición de 1986). Pág. 800.

${ }^{84}$ A.H.N. Consejos. Legajo 10.030. $n^{\circ} 2$

85 Elenco de Grandezas..... (Edición de 1976). Pág 614.

86 Reales Decretos de octubre de 1631 y 29 de enero de 1633. Por el título de Vizconde debían pagarse 750 ducados (8.250 reales), por el de Marqués o conde 1.500 ducados (16.500 reales) y 8.000 (88.000 reales) por la Grandeza que llevaba asociado el título de Duque. Por los derechos de sucesión 4.000 ducados. MORAles MOYA, A.: Op. Cit. Págs 671-673.

87 El Duque de Berwick, por ejemplo debía pagar, en 1789, 36.000 reales al año en concepto de lanzas ya que poseía una Grandeza, tres Ducados (Berwick, Veragua y Liria), tres Marquesados (de la Mota, Jamaica y San Leonardo) y tres Condados. A.H.P.M. Protocolo 20.502.

${ }_{88}$ En 1789 el Marqués de Villamejor y Vizconde de Irueste arrastraba 21.600 reales de vellón en concepto de deuda a la Real Hacienda del pago anual de 5.400 reales por los dos títulos: el Marquesado y el Vizcondado. Ibidem, fol. 65-66 r.

89 Morales Moya, A. Op. Cit. pág. 808.
} 
La mayoría de los nobles titulados presentes en el Ayuntamiento de Guadalajara eran además caballeros de Ordenes militares, 10 de 17, y la mayoría de ellos eran señores de vasallos. En realidad, ambos pasos seguían un mismo proceso de ascenso social: se compraba un señorío sobre el que poder titularse, y a continuación se solicitaba un expediente para la consecución de un hábito en alguna Orden militar, o viceversa. Después, si era posible, se compraba el título nobiliario. Frecuentemente el afianzamiento y el lustre social de un noble con título heredado eran reforzados con la adquisición de un hábito de Orden, especialmente en el XVII en que no poseer hábito era un desdoro.

\section{Los CABAlleros de ORdenes Militares.}

Veintitrés regidores de Guadalajara tuvieron hábito de alguna de las tres órdenes militares de Santiago, Calatrava o Alcántara, un 20\%. Según Domínguez Ortiz conseguir un hábito de Caballero de Orden Militar generó un interés desmesurado por el peldaño más bajo del escalafón nobiliario, los hidalgos ${ }^{90}$ y es curioso observar que la inmensa mayoría de los padres, tíos o hermanos de los miembros de la nobleza titulada presente en el Ayuntamiento de Guadalajara y que eran caballeros de Ordenes, recibieron un hábito: la totalidad de los hijos del primer Conde de la Vega del Pozo fueron caballeros de hábito ${ }^{91}$ y uno de la de San Juan ${ }^{92}$; el padre del Marqués de Andía93, los dos hijos de D. Juan de Goyeneche, el hijo del primer Marqués de Valbueno, el de Moriana: observemos que entre la mayoría de los regidores titulados la concesión del hábito precedió a la del título nobiliario. También entre los padres de los demás regidores de Guadalajara se dieron profusamente, porque en total se concedieron 18 hábitos entre los padres de nuestros regidores (un 15,65\%) cifra ligeramente menor que la de sus hijos ( 23 caballeros y un $20 \%$ del total de regidores), lo que demuestra que los capitulares del Ayuntamiento entre 1718-1788 mantuvieron las posibilidades de promoción social nobiliaria de sus padres al conseguir la cruz en el pecho que, indirectamente y junto con otros méritos, el regimiento les ofrecía.

\section{HABITOS DE CABALLEROS DE ORDENES MILITARES ENTRE LOS PADRES DE LOS REGIDORES DE GUADALAJARA ENTRE 1718-1800.}

\begin{tabular}{lcccc}
\hline & SANTIAGO & CALATRAVA & ALCANTARA & TOTAL \\
Número de Caballeros & 11 & 6 & 1 & 18 \\
\hline
\end{tabular}

90 Domínguez Ortiz, A. «Instituciones políticas y grupos sociales».. Op. Cit. Pág. 16.

91 D. Felipe y D. Mateo López de Dicastillo de la de Alcántara, D. Agustin de la de Calatrava y el Alférez mayor D. Francisco Javier de la de Santiago.

92 D. Félix de Dicastillo.

93 D. Fernando Remírez de Baquedano, caballero de Calatrava, al igual que su hijo. 
Tal prestigio supuso conseguir un hábito que, sobre todo en la época de $\mathrm{Fe}-$ lipe IV, se concedieron de forma continuada ${ }^{94}$. El efecto conseguido fue no sólo una inflación, sino una desvalorización social de los mismos. Ya se había impuesto la costumbre de conceder el hábito de una Orden a los procuradores de Cortes por sus servicios y Domínguez Ortiz señala que acabaron pidiéndose por las cosas más inverosímiles, por ejercer puestos burocráticos, económicos, e incluso por haber toreado en público ${ }^{95}$. Por ello, desde 1652, las Ordenes extremaron el rigor en las probanzas de méritos para el ingreso ${ }^{96}$. Pero aún así existían mecanismos de acceso, sobre todo la decisión regia ${ }^{97}$, desvirtuándose a lo largo de los siglos XVII y XVIII el originario y exclusivo carácter militar medieval de las Ordenes al ingresar buen número de pretendientes, por ejemplo, de Burgos, Sevilla y Cádiz con antecedentes mercantiles y comerciales ${ }^{98}$. Por ello, en parte, a partir del reinado de Carlos II dejaron de venderse hábitos, aunque el interés por ellos continuó en el siglo XVIII'99.

Algunos de los regidores de Guadalajara recibieron, para ellos o familiares, mercedes de hábito exclusivamente por participar en el sorteo de la Diputación de Millones en los últimos años del reinado de Carlos II y en conformidad por la prorrogación de los servicios de millones. En 1698 se concedieron a los regidores de Guadalajara, además de otras mercedes, 6 hábitos: a un hijo de D. Manuel Fernández de Lasarte ${ }^{100}$, al del Marqués del Valle de Carrato, a un cuñado de D. José Antonio de Torres, a un sobrino de D. Francisco del Castillo, otro de D. Rodrigo de Gamboa, y a D. Gerónimo Magán uno «para ayudar a su hermana a tomar estado» ${ }^{101}$, a D. Domingo de Zúñiga, ya caballero, «S.M. le tendría presente en las vacantes de encomiendas» ${ }^{102}$. En $1705^{103}$ se concedieron otros 3:

${ }_{94}$ Sólo la Orden de Santiago nombró entre 1641-45, 542 caballeros. Ibidem. Pág 16.

95 Domínguez OrTIZ, A.: Las clases privilegiadas ... Op. Cit., pág. 66.

${ }^{96}$ Han sido de gran utilidad los diferentes Catálogos e Indices de Caballeros de las distintas Ordenes Militares publicados por VIGNAU, V y UHAGON, F.: Indice de pruebas de los Caballeros de Santiago desde el siglo XVI hasta la fecha. Madrid, 1901 ; e Indice de pruebas de Calatrava, Alcántara y Montesa desde 1501 basta la fecha. Madrid, 1903; igualmente los de CADENAS Y VICENT, V.: Caballeros de la Orden de Santiago. Siglo XVIII. 7 vol. Madrid. 1977; y Caballeros de la Orden de Calatrava que efectuaron sus pruebas de ingreso durante el siglo XVIII. Madrid. 1986.

97 Recordemos la flamante cruz de Santiago que llevaba Velázquez, en cuya consecución tuvo considerable influencia Felipe IV.

98 Ya hemos visto la personalidad asentista y comerciante de las familias de algunos de los regidores.

99 Ibidem. Págs 58 a 70.

${ }^{100}$ Hábito que llevará el marido de su hija, D. Felipe Monge de Soria, caballero de Santiago.

101 Según Álvarez-COCA, $\mathbf{M}^{\mathrm{a}}$ Jesús en: «La concesión de hábitos de Caballeros de las Ordenes Militares: procedimiento y reflejo documental (siglos XVI-XIX), en Cuadernos de Historia Moderna, $\mathrm{N}^{\circ}$ 14. Madrid, 1993. Págs 277-279, fueron frecuentes los «pasos de merced de hábito» de una persona a otra, recurso que empleó la Corona para premiar a personas que, posiblemente, no reunían requisitos para recibir un hábito, pero se les facultaba para traspasar mercedes (pág. 289).

102 A.M.GU. Libro de Acuerdos de 1698. Sesión de e de octubre de 1698.

${ }_{103}$ Libro de Acuerdos de 1705. S/f.

Hispania, LXII/2, núm. 211 (2002) 693-746 
a D. Felipe Monge de Soria para uno de sus hijos ${ }^{104}$, y dos para las personas de D. Manuel Fernández de Lasarte y de D. Diego Oñez de la Torre ${ }^{105}$ «sin exceptuar el de Santiago", según Domínguez Ortiz, el más codiciado y prestigioso ${ }^{106}$.

Entre 1718 y 1800 el número de regidores perteneciente a Ordenes militares asciende a 23 , un $22,11 \%$ del total, casi la cuarta parte. Mauro Hernández establece para el Concejo de Madrid que más de la mitad de los regidores (un $52,5 \%$ ) poseían un hábito en el reinado de Felipe $\mathrm{V}$, y a finales de siglo lo vestían en torno a un tercio ${ }^{107}$; en Guadalajara, las cifras eran mucho menores a tenor de la menor importancia de esta ciudad en el siglo XVIII, pero durante la primera mitad del siglo (al menos hasta los años 30 ) las cruces cosidas estuvieron bien presentes en el pecho de sus regidores: seis regidores lo recibieron en el reinado de Carlos $\mathrm{II}^{108}$, la inmensa mayoría (14) fueron concedidos en el reinado de Felipe $\mathrm{V}$, habiendo sólo dos regidores que lo recibieron con Carlos III ${ }^{109}$; desconocemos un caso ${ }^{110}$.

La pertenencia a cada Orden viene reflejada en el siguiente cuadro:

\section{CABALLEROS DE ORDENES MILITARES ENTRE LOS REGIDORES DE GUADALAJARA EN EL SIGLO XVIII. (1718-1800)}

\begin{tabular}{lc}
\hline ORDEN & $\mathrm{N}^{\circ}$ DE REGIDORES \\
\hline SANTIAGO & 14 \\
CALATRAVA & 6 \\
ALCÁNTARA & 3 \\
\hline TOTAL: & 23 \\
\hline
\end{tabular}

Para recibir un hábito de caballero, según Morales Moya ${ }^{111}$, se llevaba a cabo una, en teoría, rigurosa investigación por el Consejo de las Ordenes quien a

\footnotetext{
104 Lo poseerá D. Bernardo Monge de Soria

105 Curiosamente jamás llevaron el hábito.

106 Domínguez Ortiz, A.: Las clases privilegiadas..., Op. Cit., pág. 62.

107 Hernandez Benitez, M.: A la sombra de la Corona... Op. Cit. Págs 225, 374 y 375.

108 D. Domingo de Zúñiga, Caballero de Santiago; D. Agustín Caniego de Guzmán, Caballero de Calatrava y D. Juan de Orcasitas Avellaneda y su hijo D. Juan de Orcasitas Oleaga, Caballeros de Alcántara; D. Antonio de Otazo, Caballero de Santiago y D. Francisco Ortega de Castro, Caballero de Calatrava.

${ }^{109}$ Fueron los Caballeros de Santiago D. Juan Antonio Morales Díaz Coronel y D. Manuel Ruiz de Mazmela y Castellanos

110 D. Lucas de Baraya, caballero de Alcántara.

111 Morales Moya, A.: Op. Cit., págs 599-601.
} 
partir de la genealogía y tras secreta información de otros caballeros reunía documentación y recababa todo tipo de datos, preguntando a testigos sobre la hidalguía y limpieza de sangre de los familiares, si eran cristianos viejos, habían practicado comercio u oficios viles y mecánicos, gozaban de buena reputación, etc. Había que probar por línea paterna y materna hasta 8 grados, es decir 4 cuarteles, la nobleza. Los actos positivos - como las ejecutorias de hidalguía-, los padrones de hidalgos y las sentencias de las Audiencias y las dos Chancillerías, de Valladolid y Granada, tenían gran valor probatorio. Las pruebas se debían hacer para cada miembro de la familia que aspirase al hábito.

Como vemos la pertenencia a las Ordenes era incompatible con las actividades económicas comerciales, al menos a gran escala, pero frecuentemente no se cumplía: Morales afirma que 287 casos de caballeros que hicieron pruebas en los siglos XVIII y XIX tenían ascendentes que practicaron el comercio ${ }^{112}$. En el caso de nuestros regidores, ¿cómo llamaríamos a los Goyeneche, abastecedores de paños y uniformes al Ejército con la producción de las fábricas de La Olmeda y Nuevo Baztán, sino grandes comerciantes al por mayor cuyo comprador era el Estado?.

El procedimiento de concesión del hábito, estudiado por Alvarez-Coca ${ }^{113}$, tenía tres pasos:

a. Se presentaba por el pretendiente un «Memorial» al Rey, que recibía toda la información y comprobaba la veracidad de los datos (a tenor de las investigaciones del Consejo de Ordenes).

$b$. El Monarca decidía si era merecedor o no del hábito y enviaba un Decreto al Consejo de Ordenes, que actuaba con la decisión real.

c. El Consejo decidía finalmente si concedía o no el título de caballero a la persona que había recibido del Rey «la merced de hábito» previamente.

Así pues la decisión final recaía en el Consejo de Ordenes.

Una vez recibido y expedido el título de caballero, con los distintos expedientes generados tenía lugar «la profesión» ${ }^{114}$.

En el siglo XVIII se dejaron de vender hábitos, pero los pretendientes debían dar fianzas antes de la concesión y, una vez obtenido, pagar a la Contaduría General de las Ordenes 131.200 maravedís $^{115}$. Los caballeros tenían que

\footnotetext{
112 Ibidem, pág 601.

113 AlvareZ-CoCa Fernandez, Mª Jesús: $0 p$. Cit. Igualmente, véase Postigo Castellanos, Elena: Honor y privilegio en la Corona de Castilla. El Consejo de Ordenes y los caballeros de bábito en el siglo XVII. Valladolid, 1988.

114 No olvidemos que, al fin y al cabo, eran monjes y, como tales, profesaban en la Orden a que eran pretendientes.

115 Por ejemplo en el expediente de D. J. Antonio Morales Díez Coronel, quien tuvo que poner de fianza, en 1757, 200 ducados de plata nueva y pagar, tras la concesión del hábito, 131.250 mrs de vellón «por los servicios de su montado y galeras». A.H.N. Ordenes Militares. Expedientillo 7.719.
} 
probar asimismo para casarse la limpieza de sangre y los orígenes hidalgos de sus respectivas mujeres.

El interés en obtener un hábito era económico, por supuesto, pero no era el principal. Los caballeros contemplaban la posibilidad de recibir una encomienda, -en la práctica un señorío-, y cobrar sus substanciosas rentas, por eso la preferencia por la Orden de Santiago, que era la que más encomiendas tenía, 87 , frente a las 53 de Calatrava y las 37 de Alcántara ${ }^{116}$, aunque era una posibilidad remota para los simples hidalgos porque las ricas encomiendas siempre eran concedidas a miembros de la familia real o a la nobleza superior cortesana ${ }^{117}$. También los caballeros de órdenes recibían una asignación anual de unos 12.000 maravedís al año, (un real diario), en concepto de "pan y agua», debido al antiguo derecho que tenían los caballeros a ser sustentados con bienes de la Orden ${ }^{118}$ : en 1742, en el inventario de bienes de D. Pedro de Loaysa se contabilizan entre las deudas a percibir por sus herederos los 180 reales que se le debían por la Orden de Santiago, de medio año, en concepto de paniaguado $^{119}$. Igualmente, los hábitos eran buenos sustitutos de una dote en dinero, si ésta no era muy alta, cuando la necesidad de casar bien a las hijas era un motivo de preocupación entre los hidalgos no muy ricos ${ }^{120}$ : el hábito de D. Pedro Vázquez Garay fue aportado en las capitulaciones matrimoniales con Doña María de Gamboa, hija del regidor D. Rodrigo de Gamboa y Aledo, y tasado en 1.000 ducados $^{121}$. Otro caso en el que la merced de hábito se aportó como aumento de dote fue el del regidor y criado del Duque del Infantado D. Pedro de Loaysa ya que su mujer, $\mathrm{D}^{\mathrm{a}}$ Ana María de Isla y Moscoso, lo recibió de su tío, el también regidor D. Francisco de Tapia, tasado en 2.000 ducados ${ }^{122}$.

Pero era otro, fundamentalmente, el interés en el hábito: el prestigio social. Llevar en el pecho una roja espada de Santiago o las cruces roja y verde, respectivamente, de Calatrava y Alcántara era motivo de honra y reputación en la comunidad a que se pertenecía. En resumen, se revestían de un atributo demostrativo de nobleza que quedara bien visible ${ }^{123}$.

116 Morales Moya, A.: Op. Cit, pág. 598.

117 Domínguez Ortiz, A.: Sociedad y Estado.... Op. Cit. pág. 352.

118 Domínguez OrTiz, A.: Las clases privilegiadas.... Op. Cit., pág. 60.

119 A.H.P.M. Protocolo 15.749 , fol. 286 a $421 \mathrm{r}$.

120 Domínguez Ortiz, A.: Las clases privilegiadas... Op. Cit., pág 63

121 A.H.P.GU. Protocolo 848, s/f. Suponía casi el tercio de los bienes prometidos en las capitulaciones matrimoniales, que ascendían a 24.000 reales en bienes varios, 11.000 la merced de hábito y la promesa de la mejora en el quinto y tercio de sus bienes a su muerte. Testamento de D. Rodrigo de Gamboa y Aledo, en 1708.

122 A.H.P.M. Protocolo 15.749. 23 nov de 1742, fol.. 286 a 421 r.

${ }^{123} \mathrm{Y}$ no sólo en vida ya que a su muerte los caballeros con hábito tenían derecho a ser enterrados envueltos con su manto de la Orden respectiva, a modo de sudario. 
En el periodo estudiado llevaron hábito de Santiago los siguientes regidores:

- D. Domingo de Zúñiga y Guzmán, caballero desde $1679^{124}$, después Marqués de la Ribera.

- D. Juan Antonio de Otazo, desde 1686125.

- D. Francisco Javier de Goyeneche, desde 170126, después Marqués de Belzunce.

- D. Felipe Monge de Soria, desde $1703^{127}$.

- D. Juan de Salazar Ladrón de Guevara, desde $1711^{128}$.

- D. Francisco Javier de Dicastillo, desde 1712 ${ }^{129}$, después Conde de la Vega del Pozo.

- D. Pedro de Loaysa, caballero desde $1715^{130}$.

- D. Tomás de Iriberri, desde 1716131, después Marqués de Valbueno.

- D. Francisco Miguel de Goyeneche, desde $1728^{132}$, después Conde de Saceda.

- D. Antonio de Iriberri, $2^{\mathrm{a}}$ Marqués de Valbueno, caballero desde mayo de $1729^{133}$.

- D. Bernardo Monje de Soria, desde $1732^{134}$.

- D. Pedro de Bedoya Ossorio, desde $1739^{135}$.

- D. Juan Antonio Morales Díez Coronel, desde 1757136, y

- D. Manuel Ruiz de Mazmela y Castellanos, desde $1763^{137}$.

Caballeros de Calatrava fueron:

- D. Agustín Caniego de Guzmán, caballero desde $1680^{138}$.

- D. Francisco Ortega de Castro, desde 1696139.

- D. Juan Francisco Remírez de Baquedano, desde $1711^{140}$, después Marqués de la Ribera y de Andía.

\footnotetext{
124 VIGNaU y UhaGon: Indice de las pruebas de los Caballeros..., pág. 391

${ }^{125}$ Ibidem, pág. 258.

${ }^{126}$ A.H.N. Ordenes Militares (en adelante O.M.). Leg. 61, expte 6.251

127 A.H.N./ O.M. Expediente 5.417.

128 A.H.N./ O.M. Expte 7.437.

129 A.H.N./ O.M. Expte 4.560.

130 A.H.N./ O.M. Expte 4.515 .

131 A.H.N./ O.M. Expte 6.746.

${ }_{132}$ A.H.N./ O.M. Expte 10.192.

133 A.H.N./ O.M. Expte 10.316

${ }_{134}$ A.H.N./ O.M. Expedientillo 6.979.

135 A.H.N./ O.M. Expte 940.

136 A.H.N./ O.M. Expte 5.543.

137 A.H.N./ O.M. Expte 7.560

138 A.H.N./ O.M. Expte 425.

139 A.H.N./ O.M. Expte 1.858.
}

Hispania, LXII/2, núm. 211 (2002) 693-746 
- D. Bernardo de Rojas Contreras, desde septiembre de $1711^{141}$.

- D. Diego Fernández de la Madrid, desde $1714^{142}$.

- D. José Palacios Santander, caballero desde $1733^{143}$

\section{Caballeros de Alcántara fueron:}

- D. Juan de Orcasitas Avellaneda, desde $1680^{144}$, después primer Conde de Moriana.

- D. Juan de Orcasitas y Oleaga, $2^{\circ}$ Conde de Moriana, caballero desde 1694.

- D. Lucas de Baraya y Olea, del que desconocemos la fecha de concesión del hábito ${ }^{145}$.

$\mathrm{Al}$ igual que con los títulos nobiliarios, algunos regidores caballeros de Ordenes pertenecían a linajes a los que se concedieron profusamente los hábitos; así D. Diego Fernández de la Madrid, que provenía de una familia de regidores de Toledo, cuyo padre, D. Diego Fernández de la Madrid, y hermano, D. Alonso, fueron caballeros de Santiago en 1687 y 1672 respectivamente ${ }^{146}$. Caso análogo es el de D. Bernardo de Rojas y Contreras, cuyo padre D. Diego de Rojas, Fiscal del Consejo de Ordenes y caballero de Calatrava consiguió el hábito en dicha Orden para todos sus hijos el 14 de septiembre de $1711^{147}$, o la familia de Dicastillo citada anteriormente.

\section{LOS SEÑORES DE VASALLOS}

Ser señor de vasallos no era, en sí, una categoría nobiliaria pero, si la concesión del hábito de cualquier Orden Militar suponía un importante galardón honorífico en la escala social, el poseer la jurisdicción señorial de cualquier villa

${ }_{140}$ A.H.N./ O.M. Expte 2.177.

141 A.H.N./ O.M. Expte 11.860.

142 A.H.N./ O.M. Expte 928.

143 VignaU y Uhagon. Indice de pruebas de los Caballeros de Calatrava, Alcántara y Montesa.... Pág. 126.

144 A.H.N./ O.M. Expte 728.

145 El 23 de abril de 1746 su hermano, el también regidor de la Ciudad, D. Francisco de Baraya y Larrabe, solicita del Ayuntamiento que le de estado conocido. Expone sus antecedentes familiares, originarios de Durango, en el Señorío de Vizcaya, y su condición hidalga. Entre sus familiares cita a su hermano paterno (que no materno) D. Lucas de Baraya Olea, Caballero del Orden de Alcántara. A.M.GU. Libro de Acuerdos de 1746.

146 CADENAS Y VICENT, V. Caballeros de la Orden de Calatrava que efectuaron sus pruebas de ingreso durante el siglo XVIII. Madrid, 1986, tomo I, págs 265 y 266.

147 Sus hijos fueron D. Diego, D. José, D. Bernardo y D. Pedro de Rojas y Contreras. Ibidem, págs 251 y 252 . 
o aldea era un paso previo para la concesión de un título. Era conveniente tener una jurisdicción para poder después titularse.

Según Domínguez Ortiz fue en la época de Felipe IV cuando más ventas de vasallos hizo la Monarquía, debido a las acuciantes necesidades fiscales, y con la finalidad de aumentar los recursos de la la Real Hacienda ${ }^{148}$. Y fueron precisamente las jurisdicciones de Guadalajara ${ }^{149}$ y Madrid ${ }^{150}$ las que, por su proximidad a la Corte, más sufrieron el proceso privatizador: de la inmensa jurisdicción que Guadalajara tenía en el siglo XIV y que se extendía por la Alcarria y por la Campiña del río Henares, englobando 61 aldeas ${ }^{151}$, se fueron desgajando a lo largo de los siglos XV y XVI casi todas ${ }^{152}$, de forma tal que hacia 163624 de las 28 aldeas que le quedaban de la antigua jurisdicción habían sido enajenadas a manos de particulares, o se habían eximido comprándose ellas mismas y el proceso continuó a lo largo del reinado de Felipe IV, como han puesto de manifiesto Domínguez Ortiz, Saltillo o Juan Catalina García ${ }^{153}$. Con la compra de

148 Domínguez OrTiz, A.: «Ventas y exenciones de lugares durante el reinado de Felipe IV», en Instituciones y sociedad... Op. Cit., págs. 55 a 96. Véanse para los siglos XVI a GuILARTE. El régimen señorial en el siglo XVI. Madrid, 1962, y Moxó, S.: «Los señoríos. En torno a una problemática para el estudio del régimen señorial», en Hispania, ${ }^{\circ} 95$ y 96 y Los Antiguos señoríos del Reino de Toledo. Toledo, 1973. Igualmente SALOMÓN, NOËL. La vida rural castellana en tiempos de Felipe II. Madrid, 1973, especialmente las págs 205-212, y a SALTILLO, MARQUÉS DE. Historia nobiliaria española. Madrid, 1951, 2 vols.

149 Para el régimen señorial de la provincia de Guadalajara véase de GARCía LÓPEZ, Juan Catalina: Relaciones Topógráficas de España. Relación de Pueblos que pertenecen boy a la Provincia de Guadalajara. Madrid, 1903. Tomos 41, 42, 43, 44, 45.

150 Para Madrid véanse de LÓPeZ SALAZAR PÉRez, J. «El Régimen señorial de la Provincia de Madrid», en Torre de los Lujanes, $\mathrm{n}^{\circ}$ 24. Madrid, 1993, págs 71-114. y Alvar EzQUERRA, A.: «Arbitrismo y Nobleza», en Torre de los Lujanes $\mathrm{n}^{\circ} 28$. Madrid, 1994, págs 96 a 115.

${ }_{151}$ García Ballesteros, A.: Geografía Urbana de Guadalajara. Madrid, 1978, pág. 25.

${ }_{152}$ El proceso de señorialización del término de Guadalajara empezó pronto, a manos de la poderosa familia de los Mendoza. En 1395 adquieren Tendilla. En 1423, el Marqués de Santillana obtuvo de Juan II doce aldeas de su jurisdicción, no sin plantear conflictos con el Concejo sobre sus límites: Balconete, Retuerta, Yélamos de Arriba, Pioz, Aranzueque, El Pozo,Fuentelviejo, Armuña, Sarracines, Meco, Daganzo y Yunquera. LAYNA Serrano, F. Historia de Guadalajara... Tomo I, pág. 202.

${ }_{153}$ Algunas fueron vendidas a miembros de la alta nobleza, así Fuentelaencina y Moratilla de los Meleros en 1660 fueron compradas por el Duque de Lerma por 10.000 reales de a ocho. Pero fueron sobre todo los asentistas, los hombres de negocios y los burócratas de los Consejos quienes más vasallos compraron en la jurisdicción de Guadalajara: Yebes fue compra por el genovés Lelio Imbrea; Alovera fue vendida en 1626 a Doña Lorenza de Sotomayor, hija de un consejero de Guerra, en $6.525 .000 \mathrm{mrs}$; Chiloeches fue eximida en 1626, pero pasó en 1640 al cortesano D. Manuel Alvarez Pinto en 16.500 ducados; Taracena, Iriepal y Valdenoches por el Alcalde de Casa y Corte D. Miguel de Cárdenas en 1627; Centenera fue comprada en 1629 por D. Carlos Ibarra, Capitán General de la Armada, que a su vez compró las tres villas al anterior, en 1632, por 20.000 ducados, pasando a su muerte al asentista D. Sebastián de Cortizos Villasante por 14.000 ducados; Hontova en 1646 pasó a D. Francisco Bandrés de Abarca, Tesorero de Cruzada y regidor de Guadalajara; Quer en 1665 se autovendió al Duque de Pastrana en 6.500 ducados; Romanones e Irueste fueron compradas por el consejero de Castilla D. Juan de Morales Barnuebo en 1671 y 1647 respectiva-

Hispania, LXII/2, núm. 211 (2002) 693-746 
jurisdicciones numerosos asentistas y burócratas consolidaban una reciente posición social nobiliaria, en algunos casos dudosa, pudiéndose a la larga titular sobre ellos ${ }^{154}$. Esa era la finalidad de destinar miles de ducados a la compra de un señorío, más que el de la exigua rentabilidad económica, que se traducía en el derecho de elegir la justicia ordinaria y los oficiales municipales, las penas pecuniarias de sangre, calumnias, mostrencos y otras pequeñas rentas jurisdiccionales y a veces la escribanía de número y Ayuntamiento, pagado frecuentemente en especie ${ }^{155}$.

Entre nuestros regidores hubo 16 señores de vasallos, 15 de ellos titulados, y en la mayoría de los casos comprados recientemente con el fin de titularse, y precisamente en las cercanías de la Corte ${ }^{156}$.

Los navarros - D. Juan Francisco Remírez de Baquedano, los Goyeneche, D. Francisco Vicente de Borda, D. Francisco Javier de Dicastillo- pertenecían a la categoría nobiliaria navarra por ser propietarios de señoríos solariegos consistentes, la mayoría de las veces, en una casa-palacio, tierras y la jurisdicción de algún pequeño valle, del cual poseían las pechas y otros impuesos. Estos pequeños señoríos recibían el nombre de palacios cabos de armería ${ }^{157}$, denominación equivalente a la de cabo de linaje o primogénito y cabeza de una casa noble, y tenían el privilegio de asistir a Cortes de Navarra, además de ciertos derechos señoriales como derecho de asilo, exenciones de alojamientos de tropas, cobrar las pechas o tributos y poseer armas en número suficiente para armar a los habitantes y vecinos de su jurisdicción - la «armería»-. Interés especial tenían en mantener intactos los honores y las preeminencias del palacio y los de la parroquia (de donde frecuentemente eran patronos) donde tenían un banco con el blasón de la familia, preferencia en las procesiones, derecho a sepulcros, etc.

Ya hemos visto cómo algunos de ellos se titularon sobre las propiedades o palacios de su juridicción. Sabemos que el Conde de la Vega del Pozo, D. Francisco Javier de Dicastillo era señor de una casa palacio en Dicastillo, con asien-

mente. Domínguez Ortiz, A.: «Ventas y exención de lugares..». Op. Cit. págs. 63, 66,67, 68, 69 y 70. García LóPeZ, Juan Catalina: Op. Cit. Tomo 42 págs 433 a 439, 445, 482. Tomo 43. págs 17 a 19, 166, 432, 49 y Tomo 45, pág. 50 y 260. SAltillo. MARQuÉs De: Historia nobiliaria... Op. Cit. Págs $56,335,345$ y 346 .

${ }^{154}$ Como el asentista portugués y regidor de Madrid y Guadalajara, de origen converso, D. Manuel Cortizos de Villasante, en quien recayeron las villas de Centenera, Iriépal, Taracena y Valdenoches, que fue Vizconde de Valdefuentes (Centenera) en 1668 y después Marqués de Villaflores (Iriépal). SANZ AYÁN, C. Los banqueros... Op. Cit., pág. 454.

155 Domínguez OrTiz, A.: «Ventas y exenciones...» Op. Cit. Págs 64 y 65.

156 En las provincias de Madrid, Guadalajara, Toledo o Cuenca. Sólo Moriana del Río (en Burgos) y las villas de Villatoya y Cilanco (provincia de Albacete) quedan alejadas de la Villa de Madrid, dónde los regidores tenían sus intereses.

157 NúÑEZ DE CEPEDA, M.: «La nobleza navarra», en Hidalguía, nº 1, abril-junio de 1953, págs 113-120, igualmente Domínguez OrTIZ, A.: Las clases privilegiadas... Op. Cit., págs 172-174. y MORALES MOYA, A. Poder político... Op. Cit. Pág 807-814 y CARo BAROJA, J.: La hora navarra... Op. Cit. 
to en Cortes de Navarra ${ }^{158}$, además de poseer una vega, posesiones sobre las que se tituló su padre, el consejero D. Mateo.

D. Juan Francisco Remírez de Baquedano, Marqués de Andía, heredó el título y los palacios cabos de armería y señoríos de los lugares de Escala, San Martín de Amescoa, Zudaire y Baquedano con las pechas o tributos y la jurisdicción «alta y baja» de 11 lugares del valle de Amescoa, de los montes de Andía, Encía y de Urbasa, en 1766, y en su testamento declara ser señor del palacio de Ripodas y de los lugares de Menasa y Zuriquieta, además de ser patrono de la abadía de Andía y Urbasa, que le permitía nombrar abad a su volun$\operatorname{tad}^{159}$.

D. Juan de Goyeneche y después sus hijos, los regidores D. Francisco Javier y D. Francisco Miguel, y su nieto D. Juan Javier de Goyeneche e Indáburu poseían el pequeño señorío de Belzunce y sus pechas en Navarra, sobre el que se tituló marqués el hijo primero de D. Juan, D. Francisco Javier de Goyeneche; señorío posiblemente comprado, ya que la casa palacio de Goyenechea, en Ordoqui (Navarra), de que era cabeza el padre del asentista D. Juan la heredó su hermano y primogénito, Andrés ${ }^{160}$. D. Juan también compró el señorío de La Olmeda de la Cebolla, y fundó Nuevo Baztán (entre las provincias de Madrid y Toledo), para su primogénito y las villas de Illana y Saceda de Trasierra (en la provincia de Cuenca) para su segundo hijo, D. Francisco Miguel. En el heredero de todos ellos, D. Juan Javier de Goyeneche e Indáburu, III Marqués de Belzunce y Conde de Saceda recayeron, en 1773, además de todos los anteriores, los señoríos de Ugena - junto con el título- y Torrejoncillo, en Toledo ${ }^{161}$.

Otro de los navarros, el regidor D. Francisco Vicente de Borda y Goyeneche, marido de la hija del primer conde de Saceda, era señor del palacio cabo de armería de Yarmoz y de las pechas del de Adios ${ }^{162}$.

158 A.H.P.M. Protocolo 15.494 , fol. 186 r a 190 v. Así se titula en las capitulaciones matrimoniales con $\mathrm{D}^{\mathrm{a}}$ Rafaela Gaona Portocarrero. Sin embargo Dicastillo pertencía a la Casa de Alba y Lerín en el siglo XVIII. Véase UsUNÁRIZ GARAYOA, J.M.: Nobleza y señoríos en la Navarra moderna: entre la solvencia y la crisis económica. Pamplona, 1997

159 A.H.P.M. Protocolo 17.755, fol. 653 a 683 r, y A.H.N. Consejos, legajo 5.251, exp. 2, fol. 28 v a 29 r.

160 Caro Baroja, J.: Op. Cit., págs 82 a 84 . El palacio cabo de armería de Goyenechea, con la casa solar de Lamierrita, en Arizcun lo heredó D. Juan Francisco de Goyeneche, sobrino de D. Juan, que después fue Marqués de Ugena y con el tiempo recayeron en el hijo de Juan de Goyeneche, D. Francisco Miguel, Conde de Saceda, y sus descendientes los Marqueses de Belzunce, Ugena y Condes de Saceda. En 1774 tomó posesión en nombre de D. Juan Javier de Goyeneche III Marqués de Belzunce, Ugena y Conde de Saceda su cuñado D. Joaquín Vicente de Borda. A.H.P.M. Protocolo 20.368 , fol. 498 r.

${ }_{161}$ Comprados por otro familiar, D. Juan Francisco de Goyeneche Irigoyen, igualmente asentista y tesorero, en 1735. Caro Baroja, J.: Op. Cit. Pág. 204.

162 A.H.P.M. Protocolo 16.073, fol. 378-392 r. Capitulaciones matrimoniales con Da María Antonia de Goyeneche de 20 de junio de 1768.

Hispania, LXII/2, núm. 211 (2002) 693-746 
De los señoríos que poseían en la provincia de Guadalajara los regidores del siglo XVIII, el más antiguo es el de Miralrío. Fue vendido por Felipe II en 1578 a D. Juan Maldonado de Mendoza, por el servicio de 2.594 .397 maravedís ${ }^{163}$, quien tomó posesión el 16 de mayo de 1579; vinculado por $\mathrm{D}$. Juan Manuel de Mendoza Maldonado por testamento del 4 de febrero de $1677^{164}$ recayó en la familia Medrano al casar, a fines del siglo XVII, su hija $\mathrm{D}^{\mathrm{a}}$ Paula de Mendoza Maldonado con D. Lorenzo Valle de Medrano, padre del regidor D. Alfonso de Medrano y Mendoza, señor de Miralrío en la primera mitad del siglo XVIII.

Otros de los señoríos más antiguos en manos de una misma familia de regidores, los Torres, Vizcondes de Irueste, eran los de las villas de Irueste y Romanones ${ }^{165}$ y el de Mejorada (o Villamejor), en la provincia de Madrid, sobre los que se titularon a principios del siglo XVIII. Irueste y Romanones fueron comprados en la segunda mitad del siglo XVII por el consejero y fiscal del Consejo de Castilla D. Juan de Morales Barnuevo, caballero de Calatrava, quien completaba su ascenso comprando un regimiento en Guadalajara y vasallos en estas dos villas. Ambas villas se habían eximido, pero acabaron vendiéndose. Irueste en $1647^{166}$, pagando el nuevo señor 15.000 maravedís por vecino (tenía 70), en total 1.050 .000 maravedís, unos 30.882 reales 12 maravedís $^{167}$. Romanones, cuya exención de Guadalajara databa de 1560, fue comprada en 1671 , aunque en este caso parece que fue debido al endeudamiento paulatino de la villa, que la llevó a emitir 3 censos por un total de 21.700 reales; Morales compró la jurisdicción a cambio de redimir los 3 censos y, en 1677, cuando su heredero fue a tomar posesión de la villa, se le entregó la escritura a cambio de lo estipulado ${ }^{168}$. Mejorada, en la provincia de Madrid, fue comprada en 1593 por el también consejero de Castilla y secretario D. Francisco González de Heredia, caballero de Calatrava ${ }^{169}$. En 1672, arruinada la familia, el señorío se vendió al caballero de Santiago D. Pedro Fernández del Campo (que añadió su apellido a la villa, Mejorada del Campo), aunque la venta fue cuestionada y pleiteada por la familia Torres, en quien había recaído el mayorazgo de Heredia por herencia ${ }^{170}$. Según Alvar el señorío fue vuelto a comprar por la familia

163 Unos 76.306 reales de vellón. A.H.N. Delegación de Hacienda de Madrid. Fondos contemporáneos. Libros 7.450 y 7451 . S/f.

${ }_{164}$ A.H.P.GU. Protocolo 791, s/f, 4 de febrero y 7 de marzo de 1677.

${ }^{165}$ En la provincia de Guadalajara.

$166 \mathrm{~A}$ la que su propietario quiso cambiar el nombre por Valdemorales.

167 GARCíA LÓPEZ, Juan Catalina: Relaciones topográficas... Tomo 43, pág. 26 a 28 y DomínGUEZ ORTIZ, A.: «Ventas y exenciones de lugares...»Op. Cit., pág 66, nota.

168 Saltillo, Marqués de: Historia nobiliaria... Op. Cit. Tomo I, pág. 345.

169 Alvar EzQuerra, A.: Nobleza y Arbitrismo... Op. Cit. pág. 109

170 Fundado el 11 de marzo de 1611. SAltillo. Op. Cit. Tomo II, págs 386 a 388.

Hispania, LXII/2, núm. 211 (2002) 693-746 
Torres, quien le cambió el nombre por el de Villamejor ${ }^{171}$, sobre el que se tituló marqués D. José Antonio de Torres Morales y Heredia en 1718, siendo concedido por el Archiduque D. Carlos de Austria. El pleito, según Saltillo, fue resuelto en 1753 , declarándose nula la venta, y tomando posesión del señorío la familia Torres, ya Marqueses de la villa de Mejorada, el 19 de enero de 1754.

El endeudamiento de una villa que culmina en la autoventa a un particular se dio en más casos que el de Romanones. Camarma de Esteruelas con su despoblado de Villaviciosa sufrió un proceso parecido, y también a manos de otro regidor de Guadalajara, el asentista y abastecedor de los Reales Presidios D. Antonio Puche Doncel. Camarma había pertenecido al Arzobispado de Toledo, jurisdicción de Alcalá de Henares y por privilegio de Felipe II el 20 de agosto de 1588 compró su propia jurisdicción y villazgo en 2.133 .512 maravedís; privilegio que se volvió a confirmar por Felipe V el 13 de agosto de 1719, pero la villa debía pagar además cada 15 años en concepto de media anata 6.562 maravedís (193 reales) y la carga debió ser demasiado onerosa para la villa, ya que consiguió facultad real para venderse en pública subasta en 1720. El 14 de abril de 1720 fue comprada por el asentista D. Antonio Puche en 80.000 reales $^{172}$ y pagó otros 20.000 por la jurisdicción del despoblado de Villaviciosa ${ }^{173}$ (en total 100.000 reales) comprometiéndose a pagar la media anata y los atrasos que con la Real Hacienda tenía la villa ${ }^{174}$. A pesar de que el asentista amayorazgó el señorío en su testamento de 12 de abril de $1723^{175}$, la fundación no se llevó a cabo, ya que por las altísimas deudas dejadas a su muerte se formó un concurso de acreedores resuelto en 1727, y vendiéndose en 1776 el señorío y las pocas propiedades que quedaban a la familia en Camarma y Villaviciosa en 145.000 reales al regidor de Madrid D. Manuel José de Alebio ${ }^{176}$.

El de Puche no es el único caso de pérdida de su patrimonio a manos de sus acreedores. Otros dos señoríos que recayeron en un regidor de Guadalajara lo hicieron en un proceso parecido, ahora sobre bienes vinculados. Las más lejanas villas de Villatoya y Cilanco (o Silanco) ${ }^{177}$ fueron adquiridas por D. Juan Francisco Pacheco y Duque de Estrada, en 1685, en un concurso de acreedores a los bienes del Marqués de Baides y por el impago de un censo de 5.200.000 maravedís que uno de los mayorazgos de Pacheco poseía sobre otro mayorazgo del Marqués de Baides, que hipotecaba especialmente los señoríos de dichas villas. La difícil situación de la Casa de Baides hizo que en el concurso de acreedores

\footnotetext{
171 Posiblemente porque sus anteriores propietarios se habían titulado con el nombre de Marqueses de Mejorada.

172 A.H.P.TO. Legajo H.133, fol. 4 v-6 r. Ese mismo año compró el regimiento de Guadalajara.

173 A.H.P.TO. Leg. H.30. Catastro, fol. 643.

174 Todos los datos sobre la compra del señorío en A.H.P.M. Protocolo 19.696, fol. 520 r y ss.

175 A.H.P.M. Protocolo 15.505.

176 A.H.P.M. Protocolo 19.696 , fol. 520 y ss.

177 En la actual provincia de Albacete.
} 
se le asignaran a Pacheco ambas villas tasadas en 12.000 ducados $^{178}$, pero rematadas en 82.000 reales, a cuenta del censo ${ }^{179}$. Sobre estas villas se tituló al año siguiente; título y señoríos que pasaron a sus sobrinos $\mathrm{D}$. Luis y $\mathrm{D}$. Alonso de Arellano Pacheco, regidores de Guadalajara en el siglo XVIII.

Como vemos, el mercado de señoríos y jurisdicciones, en este caso entre particulares, no parece que cesase en al siglo XVIII. Veamos más casos y a manos de otros poderosos asentistas y consejeros, como Goyeneche o su sobrino Iriberri.

D. Juan de Goyeneche compró en 1714 la jurisdicción de la Olmeda de la Cebolla ${ }^{180}$ al consejero de Hacienda D. Francisco de Loyola en 77.000 reales de vellón ${ }^{181}$. La villa había comprando su jurisdicción por Real Privilegio de Felipe II el 22 de agosto de 1564, en 892.000 maravedís (26.235 reales), aunque pronto cayó en manos del genovés Baltasar Lomelín y tras algunas vicisitudes volvió a conseguir comprarse a sí misma ${ }^{182}$, y eximida siguió gran parte del siglo XVII, pero el 1683, el endeudamiento (mal de innumerables villas castellanas, agobiadas por los réditos de los censos y la presión fiscal) hizo que se vendiese al consejero D. Francisco Antonio de Loyola en 44.000 reales de vellón, a cambio de algunas obligaciones por parte del señor como dotarla de un pósito con 300 fanegas de trigo y dar a los vecinos 40 yuntas de bueyes para labrarlas. Loyola vendió el señorío, vasallaje, penas de cámara, de sangre, elección de justicia y la escribanía del Ayuntamiento a Goyeneche el 11 de octubre de 1714. Eso sí, el comprador, a pesar de poseer la jurisdicción, debía permitir a Loyola y sus descendientes que utilizasen el título de Marqueses de la Olme$\mathrm{da}$, recientemente adquirido ${ }^{183}$, no pudiéndose titular sobre la villa el nuevo señor; quizá por ello Goyeneche, que había comprado grandes extensiones de tierras en términos de la villa (unas 4.500 fanegas según el Catastro), había recibido el 4 de julio de 1713 facultad real para desgajarlas de su término municipal y fundar el lugar de Nuevo Baztán, de cuyo señorío sería titular su hijo, el regidor de Guadalajara Marqués de Belzunce ${ }^{184}$.

Para su segundo hijo D. Francisco Miguel, también regidor de Guadalajara, compró Illana (en el límite de Guadalajara con Cuenca) y Saceda de Trasierra (en Cuenca), villa sobre la que se tituló en 1743. pinares.

${ }_{178}$ Con la jurisdicción alta y baja, mero y mixto imperio, además de tierras, huertas, dehesas y

179 A.H.N. Consejos. Legajo 28.220, fol. 117 y ss.

180 Provincia de Toledo.

181 A.H.P.TO. Leg. H. 477, fol. 126 r-159 v.

${ }^{182}$ Quien intentó venderla a D. Alonso Núñez de Bohórquez en 1582 pero con la oposición de la villa, que inició el tanteo para recuperar su jurisdicción. Bohórquez volvió a cederla a Lomelín, dando por anulada la venta. Lomelín volvió a vender a la misma villa su jurisdicción el 2 de marzo de 1584 en 1.743 .750 maravedís. Ibidem.

${ }^{183}$ Fue concedido a D. Francisco Antonio de Loyola el 2 de marzo de 1683, el mismo año que compró el señorío, con el Vizcondado previo de la Olmeda. AtiEnZA, J. Nobiliario español. Madrid, 1954, pág, 919.

${ }^{184}$ A.H.P.TO. Leg. H-477, fol.. 126 r-199 vto. 
Otro señorío que recaerá en los Goyeneche, regidores de Guadalajara, fue el que compró D. Juan Francisco de Goyeneche, tesorero y caballerizo de la reina viuda Mariana de Neoburgo y contador del Consejero de Hacienda, y sobrino del asentista $\mathrm{D}$. Juan. Siguió los pasos de su tío y compró el 31 de abril de 1734 al Cabildo de Toledo, patrón del Hospital de Santa Cruz, el señorío de Ugena y el despoblado de Torrejoncillo ${ }^{185}$ en 298.652 reales y $32 \mathrm{mrs}$, sobre el que se tituló al año siguiente ${ }^{186}$. El señorío pasó en 1773 (14 de octubre) a D. Juan Javier de Goyeneche Indáburu, III Marqués de Belzunce, II Conde de Saceda, regidor de Guadalajara y nieto del asentista D. Juan ${ }^{187}$.

D. Tomás de Iriberri, consejero y tesorero de Guerra en el Consejo de Hacienda, siguió, igualmente, el ejemplo de su tío Juan de Goyeneche y compró una gran hacienda en Valbueno, en las proximidades de Guadalajara, acompañada del señorío y la jurisdicción del lugar. Valbueno, que era una aldea de Guadalajara, fue vendida por Felipe III al monasterio y monjes jerónimos de San Bartolomé de Lupiana el 11 de marzo de $1628^{188}$, quienes disfrutaron del señorío hasta el 27 de mayo de 1726 en que.lo vendieron a Iriberri en 78.659 reales de vellón ( 77.000 reales por derechos de señorío, vasallaje, mero y mixto imperio y penas de cámara, y 1.650 reales por la escribanía de número y de Ayuntamiento); además, compró al monasterio tierras, viñas y olivares tasados en 631.350 reales ${ }^{189}$. Sobre el señorío se tituló 6 años más tarde.

Finalmente, el alguacil mayor del Consejo de Ordenes, el Conde de Moriana (después tesorero de Hacienda), poseía los señoríos de las próximas villas de Camarma del Caño ${ }^{190}$ (o de Moriana) y de Galápagos ${ }^{191}$ (con el término de Santa Catalina). Galápagos fue comprada en 1698, en 55.000 reales de vellón ${ }^{192}$, y

\footnotetext{
${ }^{185}$ Señorío, servicio ordinario y extraordinario, además de tierras, pastos y dehesas.

186 Estaban incluidas las alcabalas, los cientos, el servicio ordinario y extraordinario, la escribanía de número y los oficios de justicia. CARo BAROJA, J.: Op. Cit., pág. 204 afirma que fue comprado el 1 de agosto de 1733, pero según el Protocolo 19.391. del A.H.P.M., fol. 788 r a 825 vto, en que aparecen tasados los bienes de su mayorazgo, la fecha es 31 de abril de 1734, ante el escribano de Toledo Gaspar de Romaní y Santander.

187 Ibidem, fol. 788 r. Dado el 14 de octubre de 1773 a D. Juan Javier de Goyeneche e Indáburu.

188 Sobre todo lo referente a la venta del señorío de Valbueno A.H.P.M. Protocolos 14.642, (fols $84-168$ r) y 16.708 , (fols 101 r-140 vto).

189 Unas 1.604 fanegas de tierra, 4.404 olivos y 9.013 vides. Ibidem.

190 A.H.N. Fondos Contemporáneos. Delegación de Hacienda de Madrid, libro 172, s/f. «A la $2^{a}$ pregunta dijeron que esta dicha villa es del Conde de Moriana, residente en Madrid y que por razón de dicho señorío no percibe emolumento alguno más que una docena de pollas que se le dan por vía de regalo por Pascua ... y sólo tiene el derecho de nombrar los oficios de Xusticia en los Pleytos..."

191 Ambos en los límites de las actuales provincias de Guadalajara y Madrid.

192 A.H.N. Fondos contemporáneos. Delegación de Hacienda. Libros 7.450 y 7.451. La villa había conseguido eximirse de la jurisdicción del Arzobispado de Toledo el 25 de noviembre de 1585, por 2.651.087 maravedís, pero a fines del XVII la pobreza y gastos que arrastraba (debía a la Real Hacienda 22.000 reales y estaba cargada con dos censos) la llevaron a pedir facultad para vender su jurisdicción al mejor postor, en subasta pública. El 23 de agosto de 1698 la compró el Conde de
} 
en 1709 compró Camarma del Caño (a la que cambió el nombre por Camarma de Moriana) en 34.516 reales y 16 maravedís, la misma cantidad por la que la villa se eximió de la jurisdicción de Guadalajara en $1648^{193}$. Posiblemente también poseyese Moriana del Río, en Burgos (sobre la que se tituló), pero debió venderla (estaba muy lejos de la Corte), porque no era señor de ella en 1709 , al comprar Camarma, y a su muerte no estaba entre sus señoríos; en 1752, esta villa pertenecía D. José María de Castrejón ${ }^{194}$.

Así pues, un señorío en las próximas provincias de Madrid, Toledo y Guadalajara costaba, en la primera mitad del siglo XVIII, en torno a los 70.000 reales de vellón de media; por supuesto variaba según la extensión de la jurisdicción y sobre todo por el número de vecinos, aunque los lugares de los nuevos señores no parecen muy poblados ${ }^{195}$, e incluso parecen tener un especial interés por los despoblados, cuya jurisdicción podían desgajar de sus respectivos términos municipales, convirtiéndolos en simples propiedades o al contrario, pasando una propiedad a ser un señorío.

Mucho nos dice sobre la finalidad de la compra del señorío la actitud de estos nuevos señores, casi todos buenos apoyos económicos de Felipe $\mathrm{V}$ en el Consejo de Hacienda, como los Orcasitas, los Goyeneche o los Iriberri: poseer una villa o una jurisdicción, aunque fuese pequeña, para titularse después. Puche fracasó, pero el objetivo era el mismo. Otra actitud nos confirma este comportamiento: una vez conseguido el título nobiliario, si el señorío no se vincula en un mayorazgo, frecuentemente se vende; el hijo del primer Marqués de Iriberri, Don Antonio, menos solvente que su padre, vendió en 1755 el señorío de Valbueno junto con las propiedades en 697.272 reales (con la carga de un censo de 277.115 reales) al indiano, D. Angel Ventura Calderón, Regente del Tibunal y Audiencia de Lima, convertido hacía poco en Marqués de Casa Cal-

Moriana. D. Juan de Orcasitas Avellaneda por 55.000 reales, al contado y en monedas de oro y plata. A.H.P.GU. Legajo 618. Autos Generales del Catastro de Galápagos, s/f.

193 A.H.P.GU. Protocolo 849, s/f. Escritura de venta de 22 de octubre de 1709 . La villa se había eximido de la jurisdicción de Guadalajara el 30 de octubre de 1648, pagando 1.173 .562 maravedís. A principios del siglo XVIII la villa, con treinta y tres vecinos y cinco viudas, sin bienes de propios y que arrastraba, desde 1703, diversas deudas (entre ellas 18.937 reales en concepto de sisas, alcabalas y el servicio ordinario a la Real Hacienda), pidió real facultad para venderse, encontrando comprador en el Conde de Moriana que pujó por la misma cantidad con que la villa se había eximido medio siglo antes. Con el dinero, la villa liquidó las deudas.

194 Calonge Matellares, Mª.P., García ZarZA, E. y Rodríguez SánChez, Ma . E.: La España del Antiguo Régimen. Estudios históricos editados por Miguel Artola. Fascículo III. Castilla la Vieja. Universidad de Salamanca, 1967. Pág.126.

195 A mediados de siglo, según el Catastro de la Ensenada, Romanones tenía 78 vecinos, Irueste 44, Camarma de Moriana 37 y Galápagos «treinta y seis viudas y seis menores». Más poblado aparece hacia 1720 Nuevo Baztán, a tenor del desarrollo de las diversas fábricas que creó su señor, con 80 vecinos (unos 500 habitantes) según BLANCO, B. y de BENITO, F.J.: «Nuevo Baztán y el prerreformismo borbónico.. Op. Cit, pág. 291) 
derón ${ }^{196}$, pero sin ninguna villa jurisdiccional ${ }^{197}$; y los Puche vendieron sus señoríos de Camarma y Villaviciosa para pagar las deudas a algunos de sus acreedores, precisamente a otro regidor, D. Manuel José de Alebio, en este caso de la Villa de Madrid ${ }^{198}$.

Pero, aparte de la clara finalidad social de titularse sobre el señorío, en sí éste era poco rentable económicamente. Los derechos de jurisdicción, justicia y vasallaje se traducían en unos pocos reales, en algunos capones y gallinas entregados en fechas señaladas, y las escribanías se proveían normalmente sin mediar una contrapartida económica para el señor ${ }^{199}$. En cambio, sí que eran rentables los impuestos que en cada villa de señorío se generaban para la Real Hacienda, impuestos como las alcabalas o los cientos, y la contribución a la fiscalidad religiosa: diezmos y tercias, sobre todo. De ahí el interés de los señores por poseerlos, veámos algunos ejemplos entre los regidores de Guadalajara.

Entre los señoríos que los Torres Morales, Marqueses de Villamejor y Vizcondes de Irueste poseían en el XVIII, estaban Mejorada, Irueste y Romanones. Las alcabalas de estos lugares les pertenecían por haber sido compradas anteriormente; así, el secretario González de Heredia (del que eran herederos) compró en 1611 las alcabalas de Mejorada, en precio de 40.000 maravedís al millar, que le rentaban al año 70.000 maravedís $^{200}$ (unos 2.060 reales), igualmente D. Juan de Morales Barnuevo compró las de Romanones en 1636 y las de Irueste, en 1643 y Alonso de Barnuevo el servicio ordinario y extraordinario de estas dos últimas villas en forma de un juro de 55.624 maravedís de renta anual ${ }^{201}$, no así los cientos o las tercias, privatizadas en otras personas: las tercias de Romanones pertenecían desde 1464 a un mayorazgo de la familia Zúñiga y que por decreto de 4 de agosto de 1708 se concedieron, de nuevo, a los

196 El 12 de enero de 1734.

${ }_{197}$ A.H.P.M. Protocolo 16.448 , fols 310 r-368 v, y 698 r-v.

198 A.H.P.M. Protocolo 19.696 , fols 520 r y ss.

199 En 1752, el señor de Miralrío recibía, al año, 17 reales y 22 maravedís; el Vizconde de Irueste recibía, «por agasajo», 160 reales en Irueste y 120 en Romanones por el derecho de nombrar justicia (A.H.P.GU. Catastro, legajo 940, fols 299 v-230 r.); el Marqués de Valbueno recibía 48 reales "en especie de 6 pares de gallinas que le regalaban en Pascua..» (A.H.P.GU. Catastro. Leg. 1:575. Autos Generales, s/f); el Conde de Moriana 30 reales por la mitad de las penas de cámara y otros 60 «importe de unas aves de regalo que por Navidad se le hace.», (en total 90 reales) en Galápagos (A.H.P.GU. Catastro. Leg. 618. Respuestas generales, s/f) y en su villa de Camarma "por razón de dicho señorío .. no percibe emolumento alguno más que una docena de pollas que se le dan por vía de regalo por Pascua de Navidad..»(A.H.N. Fondos contemporáneos. Delegación de Hacienda. Libro 176)

${ }^{200}$ LÓPez SAlazAr García, J.: «El régimen señorial..» Op. Cit. pág. 111. Sin embargo, en 1752, en sus villas de Irueste y Romanones los cientos los poseía el Duque del Parque (que le rentaban unos $200 \mathrm{rs}$ ), las tercias de Irueste pertenecían a la Casa del Infantado y las de Romanones el Marqués de la Ribera. A.H.P.GU. Legajos 762 y 1.257 . Autos generales del Catastro de Irueste y Romanones respectivamente.

${ }^{201}$ A.H.P.M. Protocolo 19.766, fol. 485 r-v; en el que vienen especificados todos los mayorazgos del Marqués de Villamejor y Vizconde de Irueste, su composición, tasación total y renta anual, en 1763. 
Marqueses de la Ribera (herederos de los Zúñiga), a quienes le reportaban al año la cantidad de 33.580 maravedís ( 987 reales $22 \mathrm{mrs}$ ), 52 fanegas y 3 celemines de trigo, y 30 fanegas y 7 celemines de cebada ${ }^{202}$.

D. Juan de Goyeneche, asimismo, compró las alcabalas y cientos de casi todas sus villas y lugares: las de Illana fueron compradas por 224.000 reales de vellón ${ }^{203}$, y poseía las alcabalas y cientos de Villar del Olmo, que le rendían anualmente 1.550 reales $^{204}$, y las de la Olmeda, que le rendían anualmente 700 reales de vellón ${ }^{205}$. En Nuevo Baztán poseía además de las alcabalas (que le rentaban otros 700 reales) el derecho de cuarteles, y sobre todo el monopolio del abasto de carnicerías, tabernas, tiendas y mesón y los réditos de un censo cedido por la villa (que rentaban al año 1.440 reales), además de los diezmos y primicias: en total 6.144 reales $^{206}$. Las alcabalas, cientos y servicio ordinario y extraordinario de Ugena y Torrejoncillo rentaban al año unos 158.182 maravedís (4.652 reales $14 \mathrm{mrs})^{207}$. El señorío sí era, pues, lucrativo para los Goyeneche.

En lo que también estaban interesados los nuevos señores era en adquirir tierras y propiedades, a veces con la clara finalidad de convertirlas en jurisdicción propia; o al contrario, una vez poseída la jurisdicción de un despoblado convertirlo en una dehesa o en una explotación agraria: el Vizconde de Irueste poseía en propiedad el despoblado de Albatajar, perteneciente a la villa de Fuentelahiguera ${ }^{208}$, compuesto por unas 870 fanegas (una dehesa de 220 fanegas y 650 fanegas de tierras yermas) ${ }^{209}$, por cuya jurisdicción pleiteó en $1747^{210}$, consiguiéndola, ya que el IV Marqués de Villamejor, en 1790, se titulaba señor de Albatajar (además de Mejorada, Romanones, Irueste y Valdevelasco). Ya hemos visto como D. Juan de Goyeneche desgajó del término de la Olmeda de la Cebolla las 4.500 fanegas que convirtió en un coto redondo, consiguiendo la jurisdicción sobre la que fundó el poblado de Nuevo Baztán. Su sobrino D. Juan Francisco de Goyeneche compró junto al señorío de Ugena el despoblado de Torrejoncillo, y D. Antonio Puche la jurisdicción y tierras del despoblado de Villaviciosa, que tenía 1.862 fanegas, convirtiéndola en una gran explotación agraria ${ }^{211}$. El Marqués de la Ribera y Andía poseía, desde el

202 A.H.P.GU. Legajo 1.257 fol. 18 y ss.

203 A.H.N. Consejos, legajo 11.544.

${ }^{204}$ A.H.P.TO. Legajo H.843, fol. 22 vto. Compradas a un particular.

205 Concedidas por Felipe V el 26 de abril de 1710.

206 Ibidem. Aún así él debía pagar por alcabalas, cientos, millones, gastos de justicia, cuarteles y diezmos a la Parroquia de Nuevo Baztán 3.948 reales. La diferencia le dejaba un beneficio de 2.196 reales.

207 A.H.P.M. Protocolo 15.796, en que vienen tasados los bienes de D. Juan Francisco de Goyeneche, Marqués de Ugena.

208 En Guadalajara.

209 A.H.P.GU. Catastro. Legajo 602, fol 326-327 r.

210 A.H.P.GU. Protocolo 3709/8, fol. 31 r. La villa la consideraba como bienes comunes de ella, mientras el Marqués decía pertenecerle como bienes de un mayorazgo fundado en 1383.

211 A.H.P.TO. Legajo H-30, fol 645 r. 
siglo XVI ${ }^{212}$, el despoblado de Albolleque, cerca de Guadalajara ${ }^{213}$ que estaba compuesto por 2.000 fanegas de tierras yermas, con una casa de labor, graneros, pajares y caballerizas; en 1761 fue tasada en 330.000 reales, convirtiendo de ella 1.300 fanegas en una dehesa ${ }^{214}$. Cuando D. Tomás de Iriberri compró a los monjes jerónimos de Lupiana en 1726 el señorío de Valbueno lo acompañó de la compra de 1.616 fanegas de tierras de labor, 4.404 olivos y 9.013 vides, además de una casa, huertas, molino y olmos ${ }^{215}$ con la clara finalidad de poseer una gran y rentable explotación agraria. Finalmente, el Conde de Moriana poseía, en Galápagos, en 1752 $216,1.670$ fanegas de tierras (de las cuales 300 correspondían a una dehesa boyal), con 39.565 vides y 13.200 olivos posiblemente comprados en fechas próximas a la adquisición del señorío.

Sin embargo, otros regidores apenas poseían propiedades en sus jurisdicciones. Según el Catastro de Ensenada el Vizconde de Irueste no poseía ninguna propiedad en esta villa ${ }^{217}$, ni tampoco el señor de Miralrío en la suya ${ }^{218}$, pero eran las excepciones.

\section{LOS HIDALGOS}

El resto de los regidores de Guadalajara eran, al menos en teoría, hidalgos. De algunos tenemos constancia, aproximadamente de unos 48 , ya que consiguieron ejecutoria de nobleza, o la documentación nos dice explícitamente que lo son $^{219}$, pero en varios casos el origen social de los regidores es, cuando menos, dudoso.

Los «Libros de Familias de Legos» del Catastro de Ensenada ${ }^{220}$, en 1752, nos especifican la condición social noble de algunos «caballeros regidores» y su familia, como D. Alfonso de Urbina Pimentel y su hijo D. Félix, de D. Juan Bautista Clavero, de D. Antonio de Oñana, de D. Miguel de Torres y Contreras y sus hijos, de D. Diego de Yanguas «caballero bijodalgo», de D. Manuel de

212 Por un mayorazgo fundado en 1523 por el caballero D. Pedro de Guzmán.

213 Sita entre Guadalajara, Alovera, Los Santos y Chiloeches, a cuya jurisdicción pertenecía.

${ }^{214}$ A.H.P.GU. Protocolo 375, s/f.

215 A.H.P.M. Protocolo 14.642 , fol. 84 r a 168 r.

216 A.H.P.GU. Catastro. Legajo 623. Haciendas de legos, fols 106r-140 v.

217 A.H.P.GU. Catastro. Legajo 767.

218 A.H.P.GU. Catastro. Legajo 940.

219 Hemos considerado hidalgos los que las fuentes documentales nos especifican claramente su condición social, sobre todo los Libros de familias de Legos del Catastro de la Ensenada del A.H.P.GU., los que consiguieron alguno de los oficios reservados al estamento noble en Guadalajara como ser Alcalde de la Hermandad o Procurador General por el estado de hijosdalgo, algunos vecindarios hechos en 1773 y 1778 copiados en los Libros de Acuerdos, dónde se especifica la condición social por estados y, por supuesto, los que poseían o presentaban ejecutoria de nobleza, o sus familiares.

220 Tanto el Legajo 1H.75-a, del A.M.GU., como las Relaciones de Legos del Catastro del A.H.P.GU. Libros I y II, 
la Doblas, D. Antonio Fernández de Lasarte, D. Gerónimo de Zaldívar y su hijo D. Fausto; D. Juan de Dios de Gamboa lo era en la villa de Utande ${ }^{221}$, y D. José de la Cámara en la de Buitrago 222. D. Fernando Caniego de Guzmán era colegial del Colegio de Santa Cruz de Valladolid y sabemos que los Colegios Mayores universitarios eran instituciones nobiliarias al exigir a sus miembros desde muy pronto hidalguía y limpieza de sangre, y pertenecer a ellos se consideró como una prueba nobiliaria ${ }^{223}$. Algunos habían sido elegidos para los cargos de alcaldes o procuradores del estado noble, distinciones más bien honoríficas dentro del Ayuntamiento de Guadalajara antes de acceder al regimiento ${ }^{224}$.

Los antecesores de algunos regidores, o ellos mismos, más recientemente, habían pleiteado por conseguir una carta ejecutoria de nobleza de sangre expedida por la Real Chancillería de Valladolid, dado que la mayoría procedía de la mitad norte de la Península, especialmente de las provincias vascas ${ }^{225}$. Aunque en el siglo XVII se vendieron numerosas hidalguías, Domínguez Ortiz afirma que se cotizaron $\operatorname{poco}^{226}$ y un hidalgo de privilegio (con la hidalguía comprada) no tenía el mismo valor a los ojos de las viejas familias hidalgas (la nobleza de sangre), quienes despreciaban a estos nuevos advenedizos. En el siglo XVIII apenas se vendieron. Según Morales Moya ${ }^{227}$ las pruebas para certificar una hidalguía solían ser bastante rigurosas, pero existían mecanismos dudosos o fraudulentos para obtenerlas como los expuestos en 1652 por un alcalde de la Sala de hijosdalgo de la Chancillería ${ }^{228}$, y en 1716 se recibió en el Ayuntamiento una carta del Fiscal de la Real Chancillería denunciando que últimamente se habían admitido, en Guadalajara, en el estado de hijosdalgo a personas que no lo eran, como a Francisco de la Pedraza, Manuel Martínez de Pinilla y a Sebastián de Sola y prohibiendo que, en adelante se les tuviera por tales ${ }^{229}$.

Para la hidalguía se debía acreditar que varias generaciones de una misma familia no habían estado inscritas en los libros y padrones de pecheros, haber obtenido exención fiscal de moneda forera o del servicio ordinario y extraordinario, haber prestado servicios militares, petenecer a cofradías nobiliarias pero

${ }^{221}$ A.H.P.GU. Catastro. Legajo 1.564. Familias de legos, s/f.

${ }^{222}$ A.H.N. Fondos contemporáneos. Delegación de Hacienda de Madrid. Libro 161. Familias de Legos. fols 5 r-6 vto.

223 FAYARD. J.: Op. Cit., pág. 45.

${ }^{224}$ D. Domingo González Viejo, por ejemplo en 1775 y 1776 como Alcalde y 1788 como Procurador por el estado noble respectivamente.

${ }^{225}$ La Real Chancillería de Valladolid, tenía jurisdicción para los pleitos de los territorios situados al norte del río Tajo.

226 DomínGUez ORTIZ, A.: «Instituciones políticas y grupos sociales», en Instituciones y sociedad... , pág. 15.

227 Morales Moya, A. Op. Cit., págs 543-545.

228 B.N. Manuscrito 18.738-32. Citado por DOMínguez OrTIZ y Janine FAYARD; bien porque no había padrones que diferenciasen al estado pechero o hidalgo, o porque desapareciesen o se alterasen, borrando o incluyendo algún antepasado de un escribano.

${ }^{229}$ A.M.GU. Libro de Acuerdos de 1716, en Valladolid a 4 de junio. Sola llegó a ser regidor. 
sobre todo de haber ejercido oficios reservados a nobles, como ser alcalde de la Hermandad por el estado noble de la villa o ciudad en que se avecindaban. La elección al cargo de alcalde de la Hermandad por el estado de los Hijosdalgo era tan importante para acreditar la condición nobiliaria que los regidores procuraban que sus hijos fuesen nombrados por el Ayuntamiento; no en vano en 1756, pedía el regidor D. Gerónimo de Zaldívar, airosamente, que «los Caballeros Regidores queden incluidos en los nombramientos de Alcalde de la Santa Hermandad y Procurador General por el estado noble», pidiendo certificación al escribano de Ayuntamiento para él y para su hijo D. Fausto, - también regidor desde 9 de junio de ese mismo año- que acreditase su hidalguía, y dónde quedase reflejado que ambos «antes ni después de haber tenido la Honra de Capitulares..., no se les ba incluido en los repartimientos de Sevicio Ordinario, ni extraordinario, cargado Cargas, ni oficios concejiles de los que se nombran de Arquero, Depositarios, Receptores de Bulas, ni echado soldados, vagajes, ni otra especie concejil a que sólo están sujetos los hombres buenos Pecheros, y de que están exemptos los hijosdalgo notorios..» ${ }^{230}$. Su hijo había sido nombrado en 1752 alcalde por la Hermandad de hijosdalgo y quizá el interés de D. Gerónimo esté en acumular datos referentes a su condición hidalga, por la que había pleiteado en la Real Chancillería de Valladolid unos años antes, en 1741, como veremos a continuación ${ }^{231}$.

En Guadalajara existía, en el siglo XVII, una hermandad nobiliaria, la de San Salvador de Oviedo fundada en la Edad Media; Francisco de Torres nos habla de ella «...con estatutos muy apretados de nobleza y limpieza, la cual tiene ordenanzas muy notables..», en 1642 tenía como cofrades a miembros de la oligarquía urbana y concejíl de Guadalajara «.. a los Excelentísimos Sres Duques del Infantado y Pastrana, con otros señores y muchos caballeros de bábito y sin él con que está muy autorizado ...», aunque parece que en la segunda mitad del XVII ya no se juntaba ${ }^{232}$, entre estas familias estaban los Caniego, los Solís de Magaña o los Zúñiga, que poseían todos los elementos distintivos de la nobleza: mayorazgos, oficios municipales, capellanías, sepulturas y armas. Igualmente, sabemos que en los siglos XVI y XVII algunas familias de dinastías de regidores obtuvieron ejecutorias: los Torices en $1554^{233}$, la familia del Hierro en la persona de D. Diego del Hierro y Herrera en $1609^{234}$, los Palomeque en la persona del regidor D. Cristóbal Palomeque en $1635^{235}$, los Ortega de Castro, de Jadraque, en $1636^{236}$, D. Manuel de Bedoya, de Hita —antepasado de D. Vicente, D. Pedro, D. Fermín y D. José

230 A.M.GU. Libro de Acuerdos de 1756. Sesión del 9 octubre.

231 BASANTA De la Riva, A.: Archivo de la Real Chancillería de Valladolidad. Salas de Hijosdalgo. Catálogo de todos sus pleitos, expedientes y probanzas. Madrid, 1922, 4 vols. Tomo 4, pág. 64.

232 TORRES, Francisco de. Historia de la muy nobilíssima Ciudad de Guadalajara.., pág. 147.

233 Basanta de la Riva, A.: Op. Cit., tomo III, Págs 409 y 410.

234 Ibidem, tomo II, pág. 215.

${ }^{235}$ Catálogo alfabético de los documentos referentes a Hidalguías conservadas en la Sección de Consejos suprimidos del A.H.N. Madrid, 1920. Pág. 110.

236 BASANTA DE la Riva, A.: Op. Cit, tomo III, pág. 50.

Hispania, LXII/2, núm. 211 (2002) 693-746 
de Bedoya Ossorio- que pleiteó en 1666 237, o el asentista D. Juan de Goyeneche quien, en 1685, publicó la carta ejecutoria obtenida por los habitantes de valle navarro de Baztán, que tenían conseguida su nobleza desde $1440^{238}$.

También en el siglo XVIII algunos regidores o familiares suyos se apresuraron a obtener cartas ejecutorias de hidalguía, con distintas finalidades: unos la pedían para sus hijos, que iniciaban la carrera militar y a los que se exigía la hidalguía: así D. Pedro de Montoya pidió al Ayuntamiento, en 1780, que certificara la condición nobiliaria para su hijo $\mathrm{D}$. Lorenzo que pretendía ascender a oficial en el Regimiento de Infantería de Africa, donde servía; los antepasados de Montoya figuraban en 1608 y 1635 como hidalgos en los padrones que se conservaban en los archivos del palacio del Infantado, (al pertenecer el oficio de alcalde de padrones a dicha Casa), y más recientemente su abuelo obtuvo, en 1705 , el oficio de alcalde ordinario por el estado noble de la villa de Peñalver, y aunque en Guadalajara no obtuvieron los empleos reservados a los nobles, como el de procurador General o el de alcalde de la Hermandad por dicho estado, al ser él mismo, su padre, y abuelo escribanos del Ayuntamiento (y era incompatible) se les tenía «..por público y notorio..» como hidalgos de sangre ${ }^{239}$; sin embargo, en algunos de los vecindarios que se hicieron por el Ayuntamiento, en $1773^{240}$ y $1776^{241}$, en que aparece una descripción detallada de todos los vecinos, su condición social, oficios, calles y barrios donde habitaban, no aparece acreditado Montoya como noble.

Aunque los Calderón de la Barca (incluida la rama de Guadalajara) tuvieron un panegirista de su casa y armas en la figura de Felipe de la Gándara ${ }^{242}$, hubieron de certificar su condición noble, igualmente, para el ejercicio militar; D. Manuel Calderón de la Barca, hijo de D. Melchor Calderón pretendía en 1755 el oficio de cadete de la Real Armada, para lo cual necesitaba una información por parte de diversos testigos, entre ellos su padre, que afirmó ser tenido por hidalgo en Guadalajara, habiendo participado en el sorteo para diputados del Reino por el estado de hidalgos y en el sorteo de 1746 salió elegido por tal, al igual que su abuelo, igualmente diputado en 1710 y que fue regidor y alférez mayor de Guadalajara, y pertenecía, además, a la hermandad fundada en el con-

237 Ibidem, tomo IV, pág. 153.

${ }^{238}$ JUAN DE GOYENECHE. Executoria de la nobleza, antigüedad y blasones del valle del Baztán, .....

239 A.H.P.GU. Protocolo 1.077 , fol. 266 r

240 A.M.GU. Libro de Acuerdos de 1773. Realizado con la finalidad de hacer una leva de soldados entre los mozos de la ciudad y fechado el 17 de mayo de 1773.

241 A.M.GU. Libro de Acuerdos de 1776. Tenía la misma finalidad.

242 De la GÁNDara, F.: Descripción, armas, origen .... de la Casa de Calderón de la Barca y sus sucesiones continuadas.. Madrid, 1753. 
vento de las Mercedes por los hidalgos de ella ${ }^{243}$. D. Manuel recibió, parece que provisionalmente, el título nobiliario de Marqués de Poveda en $1764^{244}$.

Veamos otros ejemplos y estudiemos algunos procedimientos en los procesos hasta obtener la carta ejecutoria:

D. Gerónimo de Zaldívar, abogado, provenía de Molina de Aragón, donde su familia poseía la hidalguía desde 1558, en que se la incluyó en los padrones de hidalgos; su abuelo recibió reconocimiento de la Real Chancillería de Valladolid y ganó real provisión de hidalguía el 22 de junio de 1655; su padre fue elegido alcalde de la Hermandad del estado noble de Molina en 1687 y él mismo lo fue en 1734, antes de ir a vivir a Guadalajara; D. Gerónimo pleiteó con la villa de Iriépal ${ }^{245}$ (de donde era originaria su mujer) para conseguir quedar incluido en el estado noble, obteniéndolo en 1736. Al avecindarse en Guadalajara presentó toda esta documentación y se les reconoció a él y a su hijo D. Fausto por tales hidalgos en 10 de junio de $1741^{246}$.

D. Francisco de Baraya y Larrabe, proveniente de la villa de Durango, en Vizcaya, presentó al avecindarse en Guadalajara ejecutoria de nobleza el 23 de abril de $1746^{247}$. Su familia poseía casa solar infanzona en Durango (Vizcaya) y su hermana $\mathrm{D}^{\mathrm{a}}$ Marta de Baraya, vecina de Cifuentes, recibió ejecutoria de hidalguía de la Sala de Vizcainías de la Real Chancillería de Valladolid el 19 de enero de 1725 . Su hermano de padre D. Lucas de Baraya y Olea era, como ya hemos visto anteriormente, caballero de Alcántara.

Finalmente, veamos el caso de los Oñez de la Torre, que requiere un análisis más detallado. Los Oñez recibieron carta ejecutoria ganada a la villa de Iriépal el 24 de mayo de 1766 en las personas del escribano de Ayuntamiento D. Narciso Oñez y su primo D. Agustín ${ }^{248}$, reconociendo con ella la condición hidalga a la numerosa familia Oñez presente en el Concejo de Guadalajara desde la segunda mitad del siglo XVII y todo el siglo XVIII ${ }^{249}$. La familia había empezado a litigar por la hidalguía en 1687, en la persona del secretario, escribano de Ayuntamiento y familiar de la Inquisición Francisco Oñez de la Torre (en la documentación aparece sin el «don»), quien inició un pleito con el concejo de Iriépal - donde había comprado una heredad- al ser inscrito en

${ }^{243}$ A.H.P.GU. Protocolo 950, s/f. 8 nov, de 1755 . No hemos encontrado ningún dato más referente a esta cofradía.

${ }^{244}$ Catálogo alfabético de los documentos referentes a Títulos del Reino y Grandezas de España... Tomo I, pág. 301

${ }^{245}$ A muy pocos kilómetros de Guadalajara.

246 A.M.GU. Libro de Acuerdos de 1741. Igualmente viene en el Catálogo de BASANTA DE LA RIVA, A,: Op. Cit., tomo IV, pág. 96.

247 A.M.GU. Libro de Acuerdos de 1746, fols 44 y 45 r.

${ }^{248}$ Padre del regidor D. Ceferino Oñez de la Torre.

249 Dicha Carta executoria de bidalguía notoria de sangre en propiedad posesoria de D. Francisco Vicente y D. Narciso Oñez de la Thorre, Padre e bijo vezinos que fue y es de la Ciudad de Guadalajara a pedimiento de dicho $D$, Narciso Oñez de la torre. Correxida., se conserva en el A.M.GU., también en SALGADO OlmeDA, F.: «El proceso de ascenso social...»Op. Cit., págs 235 a 242. 
los padrones de pecheros. Según Francisco Oñez su familia había poseído desde antiguo la condición nobiliaria, la villa, sin embargo, afirmaba que «..el nominado Francisco Oñez ... reconociendo la suma pobreza de dicho Concejo y sus vecinos, maliciosamente para litigar con contrarios pobres, había comprado una beredad de olivos en término de dicha villa, con cuio pretesto havía empezado dicho litigio ... y ... que hera manifista la cautela y fraude de litigar con sus partes por hallarse (el concejo de Iriépal) inhavilitado de poder continuar dicho Pleyto por su pobreza...». Se inició una investigación para ello, trasladando las investigaciones a Guadalajara ${ }^{250}$, pero los documentos que demostraban esta condición eran los padrones de hidalgos que, con finalidad fiscal, realizaban los Ayuntamientos y en Guadalajara no se hacían repartimientos de pecheros "de tiempo inmemorial», pagándose los impuestos directos, es decir el servicio ordinario y extraordinario, no repartiéndolos entre los vecinos pecheros sino de los bienes de propios y arbitrios municipales (impuestos que desde la Guerra de Sucesión y a lo largo del XVIII, a Guadalajara se le perdonó pagar), siendo el único instrumento reconocido para reconocer la nobeza de la Ciudad el nombrar anualmente a algún hidalgo alguacil mayor, alcalde de la Hermandad o procurador por el estado noble 251 , oficios que, según hemos comprobado, no ejerció ningún miembro de la familia Oñez ${ }^{252}$. Pero los padrones sí habían existido anteriormente, y se conservaban en el archivo de la Casa del Infantado, ya que el oficio de escribano y alcalde de padrones pertenecía en propiedad a los Duques desde el siglo XV, estando anotado en ellos como hidalgos exentos los Oñez; junto a ellos estaban los testimonios de particulares, entre ellos los del alcalde y quatros del común, es decir la representación del estamento pechero, quienes afirmaron que los Oñez estaban «en opinión de» hidalgos. En 1690, Francisco Oñez de la Torre consiguió una provisión ${ }^{253}$ de hidalguía ${ }^{254}$, pero no parecieron pruebas válidas porque el pleito, que se prolongó durante el siglo XVIII por sus descendientes, se resolvió el 31 de agosto de 1765 en una sentencia negativa de la Sala de Hidalgos de la Real Chancillería, dando por no probada la condición hidalga de D. Francisco Vicente y su hijo D. Narciso. Los Oñez apelaron pero la villa de Iriépal, emplazada, no se presentó revocándose la sentencia y declarando el 5 de noviembre de 1765 a los Oñez hijosdalgo. La carta ejecutoria se les concedió el 24 de mayo de 1766. Tal vez las pruebas que demostraban la condición no-

\footnotetext{
${ }^{250}$ Donde el interesado tenía poder porque era escribano de Ayuntamiento, su hijo poseía un regimiento desde 1667 comprado por él mismo y estaba emparentado con parte de la hidalguía urbana.

251 Precisamente es lo que alegó la villa de Iriépal que afirmó que usi dicho pretendiente, su padre y abuelo fueron bixos Dalgo bubieran obtenido en dicha Ciudad de Guadalaxara los oficios de Alguacil Mayor y Procurador General que se conferían en ella a los que lo beran (sic)..."

${ }^{252}$ Recordemos además que desde 1722 hasta 1748 se suspendió el nombramiento y elección de Alcalde de la Hermandad noble de Guadalajara.

$253 \mathrm{Y}$ como tal provisional.

254 BaSANTA DE LA RIva, A.: Archivo de la Real Chancillería..., tomo III, pág. 40.
} 
ble de los Oñez fueron verdaderas, pero observemos que cuando los Oñez consiguen su ejecutoria la familia maneja ciertos mecanismos de poder que, unido a la pobreza del concejo que pleiteaba, indudablemente, influyeron en la resolución positiva del pleito, corroborando la idea de que la posesión de un regimiento o cargo público sirvió para afianzar recientes o dudosas hidalguías ${ }^{255}$.

Aún a fines del siglo XVIII tuvieron que presentar ejecutoria algunos vecinos que tenían o pretendían el oficio de regidor, como el comerciante D. Francisco de Udaeta, en $1796^{256}$, quien ya había pedido vecindad, como noble, en 1786257; D. Gerónimo Páez Xaramillo la obtuvo en $1792^{258}$ o D. Feliciano Manuel Bradi, arquitecto y maestro de obras, con origen irlandés, pero cuya familia estuvo presente en Castilla desde el reinado de Carlos II, quien ganó la ejecutoria en grado de vista y revista ${ }^{259}$ por la Real Chancillería de Valladolid el 14 de julio de $1798^{260}$. Finalmente, en 1801, la obtuvo D. Antonio Medrano y Heredia, hijo del asimismo regidor D. Antonio de Medrano y Mendoza ${ }^{261}$. Hemos incluido asimismo a D. Alberto Arias del Hierro, regidor desde 1795, y que aparece en el sorteo a la Diputación de Millones de $1806^{262}$ como Teniente Coronel de los Reales Ejércitos, al exigirse a los militares de alta graduación la condición nobiliaria ${ }^{263}$ y ser primo de los Vizcondes de Palazuelos.

Pero no creemos que otros muchos regidores, especialmente los que en la segunda mitad del XVIII compraron o ejercieron como tenientes oficios municipales, lo fuesen. En el callejero y vecindario realizado por el Ayuntamiento en 1773 sólo había 24 vecinos considerados nobles y de ellos, sólo 7 eran miembros del Cabildo municipal: el intendente Argumosa, los regidores D. José de Torres Medrano, D. Antonio de Medrano y Mendoza, D. Gerónimo de Zaldívar, D. Francisco Javier Monge y Urbina y los escribanos de Ayuntamiento D. Narciso Oñez de la Torre y D. José de Praves, y otros dos vecinos que accede-

25s EGIDO, T.: «La elites de poder....», Op. Cit., tomo XXXI, págs 133-170.

256 A.M.GU. Libro de Acuerdos de 1796.

257 Proveniente del valle de Ayala, donde recibió el oficio de Personero en los años 80 , recibió Provisión de nobleza por la Chancillería de Valladolid el 16 de diciembre de 1784. Tomó posesión de vecindad por el estado noble el 17 de marzo de 1785 en la Villa de Madrid, y su presencia en Guadalajara es debida al matrimonio con la hija del comerciante Molero. A.M.GU. Libro de Acuerdos de 1786, sesión de 6 de septiembre.

${ }^{258}$ BASANTA De la Riva, A.: Op. Cit., tomo I, pág. 73. Era asimismo miembro de la Real Maestranza de Ronda. A.H.P.GU. Protocolo1.005, fol. 51 i

259 Procedimiento lento pues suponía pleitear reiteradamente la decisión judicial aportando nuevas pruebas, hasta conseguir el objetivo.

${ }^{260}$ A.M.GU. Libro de Acuerdos de 1798. y BaSANTA DE LA Riva, A. Op. Cit., tomo I, pág. 174, junto con su hermano D. Feliciano Bradi.

261 Ibidem, tomo II, pág. 389.

262 A.M.GU. Libro de Acuerdos de 1806.

263 Especialmente desde el grado de Coronel. Véanse en este sentido ANDUJAR CaSTILlO, F.: Los militares en la España del XVIII.. Op. Cit, y BaLduQue MARCOS, L. M.: El Ejército de Carlos III...Op. Cit. 
rán en años sucesivos al regimiento: D. Francisco Javier de Torres y Medrano y D. José de Cáceres y Salinas, quien por cierto, al ser elegido en 1779 alcalde de la Hermandad por el estado noble fue cuestionado por el Síndico Personero y los quatros del común por no haber sido recibido por hijodalgo en el Ayuntamiento, lo que obligó a tener que indagar sobre sus origenes en los Libros de Acuerdos, en los que un informe constató que su bisabuelo, el regidor D. Juan de Cáceres, presentó ejecutoria en 1674, y sus hijos paticiparon en todos los oficios y elecciones a Diputación del Reino por el estado noble en Guadalajara ${ }^{264}$.

Si bien a este grupo de categoría social indefinida (casi el 10\%), su condición de notables les hacía aparecer con una situación paranobiliaria ${ }^{265}$, y eran tratados con el «don», tratamiento no muy prodigado en el Antiguo Régimen a los no nobles, no eran considerados por los hidalgos locales por tales al no tener acreditada su condición con una carta ejecutoria o con los cargos honoríficos nobiliarios. No aparecen como nobles la familia Pedroches, D. Pedro de Montoya (aunque intentó su definición posteriormente), los Pérez de Oñana, ni D. José Antonio de la Peña, que ya eran regidores en 1773, ni otros que lo serían después como: Caltañazor, Arguedas, Fernández de Lara, Morales Salomón o González de Mendoza, casi todos empleados en la administración de las rentas provinciales, en las oficinas de la Real Fábrica de Paños, en la renta de Tabacos o en la oficina de Correos, presentes en la ciudad.

$\mathrm{Y}$ es aquí donde está la verdadera naturaleza social de la oligarquía urbana, en sus empleos y profesiones, en sus salarios y rentas, aunque, no lo olvidemos, con actitudes, valores y aspiraciones nobiliarias, diferentes de su origen social, que les llevaban a comprar un regimiento, no en vano Carlos III intentó dignificar el ejercicio municipal, incluso en los oficios recientemente creados como Diputados y Personeros del Común ${ }^{266}$ y alcaldes de barrio, (aunque sólo en la villa de Madrid), reconociendo como actos positivos de nobleza el haber ejercido estos empleos ${ }^{267}$.

Ello nos lleva a analizar la actividad profesional de los regidores.

${ }^{264}$ A.M.GU. Libro de Acuerdos de 1779. Informe del regidor D. Antonio Medrano y Mendoza visto el 12 de febrero. Su padre, D. José Gregorio de Cáceres, vecino de Valdenoches, pleiteó en 1758, presentando ante la Chancillería una ejecutoria dada a D. Juan de Cáceres, vecino de Barajas, en 1633. BASANTA DE la Riva, A.: Op. Cit., tomo I, pág. 191.

${ }^{265}$ Por ejemplo los abogados, licenciados y titulados universitarios por algunas Universidades como Salamanca, Valladolid, Alcalá de Henares y el Colegio de Boloña por la concesión de Carlos I de dos Reales Cédulas en 1534 y 1535. Morales Moya, A.: Poder político.... Op. Cit. Pág. 568.

${ }^{266}$ Nov. Rec. Ley II, tit. XVIII, libro VII. Real Cédula de 26 de junio de 1766.

${ }^{267}$ Ibidem. Ley II, tit. XVIII, libro VII. Real Cédula de 6 de octubre de 1768 . Vid. MORALES MOYA, A.: Op. Cit. Pág. 571. 


\section{LA DEFINICIÓN SOCIAL DE LOS REGIDORES: LOS OFICIOS Y EMPLEOS}

Los regidores de Guadalajara no eran personas ociosas. Un estudio detallado de sus actividades profesionales paralelas (o al margen) de la actividad municipal así lo desvelan. Es más, probablemente una causa del desinterés y del absentismo en el Cabildo municipal está precisamente en esas otras actividades que los regidores tenían, mucho más lucrativas y mejor remuneradas -recordemos que desde principios de siglo hasta los años 60 no se cobraba por ejercer la actividad municipal - , y que les llevaban a desplazarse a otros lugares y ciudades, especialmente Madrid, donde se podrían promocionar profesional y socialmente. Recordemos también que ser regidor no suponía ejercer el oficio municipal de forma activa, el absentismo fue la tónica general a lo largo del siglo y no era frecuente encontrar la gestión municipal de Guadalajara en manos de más de 9 o 10 munícipes (una cuarta parte) de los 37 regimientos que la ciudad tenía en el siglo XVIII.

$\mathrm{Al}$ menos 68 regidores tenían otras actividades profesionales remuneradas, unos en el servicio a la Monarquía en la alta administración de los Consejos o de las Secretarías, en la Corte, en Audiencias o en el Ejército, pero otros muchos - la mayoría - eran pequeños burócratas en la ciudad de Guadalajara o sus proximidades y administraban como recaudadores, contables, tesoreros $\mathrm{u}$ oficiales las rentas reales, los millones y las alcabalas de la provincia, los diezmos del Arzobispado de Toledo o las rentas y haciendas de algunos nobles, especialmente de la Casa del Infantado, cuyo numeroso enjambre de servidores recibió frecuentemente un regimiento como premio - presumimos-a sus servicios.

Había también algunos profesionales, e incluso un clérigo entre los regidores del siglo XVIII. Algunos compaginaban varios oficios y actividades a la vez.

Observémoslo en el siguiente cuadro:

DEFINICION PROFESIONAL DE LOS REGIDORES

DE GUADALAJARA (1718-1800)

\begin{tabular}{|l|c|c|}
\cline { 2 - 3 } \multicolumn{1}{c|}{} & NÚMERO DE REGIDORES & PORCENTAJE \\
\hline Alta administración & 13 & $11,30 \%$ \\
\hline Servicio a la nobleza & 10 & $8,70 \%$ \\
\hline Administración provincial & 9 & $7,85 \%$ \\
\hline Militares & 7 & $6,10 \%$ \\
\hline $\begin{array}{l}\text { Administración rentas religiosas del } \\
\text { Arzobispado de Toledo }\end{array}$ & 6 & $5,20 \%$ \\
\hline Corte & 6 & $5,20 \%$
\end{tabular}

Hispania, LXII/2, núm. 211 (2002) 693-746 


\begin{tabular}{|l|c|c|}
\cline { 2 - 3 } \multicolumn{1}{c|}{} & NÚMERO DE REGIDORES & PORCENTAJE \\
\hline Abogados & 4 & $3,50 \%$ \\
\hline Asentistas/comercio & 4 & $3,50 \%$ \\
\hline Escribanos & 3 & $2,60 \%$ \\
\hline Admón Real Fábrica de Paños. & 3 & $2,60 \%$ \\
\hline Clérigo & 1 & $0,85 \%$ \\
\hline Colegial & 1 & $0,85 \%$ \\
\hline Arquitecto & 1 & $0,85 \%$ \\
\hline Sólo regidores & 47 & $40,90 \%$ \\
\hline Total & 115 & \\
\hline
\end{tabular}

* Habían ejercido el oficio antes del regimiento.

Los empleos de los padres de los regidores siguen un esquema socio profesional parecido al de los hijos, pero con algunas características diferentes:

- muchos fueron regidores, casi la tercera parte (46 casos y un $40 \%$ ), y de ellos cerca del $15 \%$ ejerció la acción municipal en la misma ciudad de Guadalajara.

- unos 22 eran pequeños burócratas al servicio del concejo, de la Casa del Infantado, abogados, escribanos, o militares (casi una quinta parte), pero apenas hay padres de regidores al servicio de la Casa del Infantado (sólo tres, mientras que hubo diez entre los regidores del XVIII); es escaso el número de padres de regidores presentes en la administración de las rentas provinciales, los millones o de las Reales Fábricas - tres casos-, y es relativamente alto el porcentaje de progenitores de regidores que fueron escribanos, siete.

Veámoslo en el siguiente esquema:

\section{DEFINICIÓN PROFESIONAL DE LOS PADRES DE LOS REGIDORES (1718-1800)}

\begin{tabular}{|l|c|c|}
\cline { 2 - 3 } \multicolumn{1}{c|}{} & NÚMERO & PORCENTAJE \\
\hline Alta administración (Consejeros) & 7 & $6,10 \%$ \\
\hline Corte & 3 & $2,60 \%$ \\
\hline Regidor & 46 & $40,00 \%$ \\
\hline
\end{tabular}




\begin{tabular}{|l|c|c|}
\cline { 2 - 3 } \multicolumn{1}{c|}{} & NÚMERO & PORCENTAJE \\
\hline Profesionales & 9 & $7,80 \%$ \\
\hline Escribanos & 7 & - \\
\hline Abogados & 1 & - \\
\hline Médicos & 1 & - \\
\hline Servicio nobleza & 3 & $2,60 \%$ \\
\hline Militares & 3 & $2,60 \%$ \\
\hline Asentistas/comercio & 3 & $2,60 \%$ \\
\hline Admón diezmos Arzob. de Toledo & 4 & $3,50 \%$ \\
\hline Sin definir & 37 & $32,20 \%$ \\
\hline ToTAL & 115 & \\
\hline
\end{tabular}

Cierto número de regidores se promocionó, siguiendo una prestigiosa carrera burocrática ${ }^{268}$, hasta llegar a la alta administración como consejeros, especialmente en el Consejo de Hacienda que, dada la gran cantidad de funciones en las numerosas oficinas, Juntas y Contadurías, se nutrió de expertos burócratas provenientes de los grupos medios urbanos (quienes frecuentemente copaban las regidurías de las ciudades) ${ }^{269}$ presentes, sobre todo, en la Sala de Millones, como comisarios electos que eran por las ciudades de voto en Cortes, como el capitán de Marina D. Manuel Ruiz de Mazmela y Castellanos, presente en la Sala de Millones desde 1775 en quien recayó la suerte de diputado de este servicio por Guadalajara y que ejerció, al menos, hasta $1783^{270}$.

También los importantes asentistas y hombres de negocios de principios de siglo estuvieron presentes en el Consejo de Hacienda, así los Condes de Moriana, D. Juan de Orcasitas Avellaneda y D. Juan de Orcasitas y Oleaga, el primero tesorero de gastos secretos de Felipe V, y de Guerra ${ }^{271}$ y Contador de fianzas de Rentas Reales ${ }^{272}$, el segundo sucedió a su padre en la Contaduría. Sustituyendo a Orcasitas como Tesorero mayor de Guerra estuvo D. Tomás de Iriberri, primer Marqués de Valbueno, y su hijo D. Antonio también fue conse-

${ }^{268}$ Fueron 13 los regidores de Guadalajara presentes en los Consejos (algo más del 10\% del total), de ellos diez lo fueron de Hacienda, dos de Indias y uno de Navarra.

${ }^{269}$ Así lo ha demostrado también para el Consejo de Castilla Janine FAYARD: Op. Cit., especialmente en las págs. 264 y 314, 315 y 316, quien afirma que cerca de un $30 \%$ de los miembros del Consejo de Castilla provenía de las oligarquías urbanas que controlaban los regimientos.

270 Lo vemos aparecer en la fundación del Banco de San Carlos, en 1782, como Diputado de Millones del Reino decano.

271 Bravo Lozano, J.: «Don Francisco de Horcasitas...». Op. Cit. Pág. 519.

${ }^{272}$ Heredado de su hermano, D. Lucas que lo compró por 1.080 .000 reales. SANZ AYAN. C.: Los Banqueros de Carlos II. Op. Cit., pág. 424. 
jero de Hacienda. Los hijos del asentista D. Juan de Goyeneche, Belzunce y Saceda, respectivamente, sin dejar de administrar los bienes privados de la Monarquía como tesoreros de la mujer de Felipe V, Isabel de Farnesio, no estuvieron, sin embargo, presentes en el Consejo de Hacienda, siendo Belzunce Tesorero y consejero de Indias, cargo venal comprado por su padre en 1707 por 440.000 reales $^{273}$; Saceda, sin embargo, permaneció al cargo de otras actividades económicas y empresariales como la gestión de la Gaceta de Madrid, o la producción fabril de Nuevo Baztán, pero no permaneció alejado de la Corte donde ejercía el cargo palaciego de gentilhombre de Cámara del Rey ${ }^{274}$. La importancia de la actividad económica y financiera de los Goyeneche al lado de la Monarquía se continuó en la tercera generación con D. Juan Javier de Goyeneche II Conde de Saceda, Marqués de Belzunce y Ugena, que tuvo un papel fundamental en la fundación del Banco de San Carlos, en 1782. ${ }^{275}$ Otros consejeros de Hacienda fueron el Marqués de la Ribera, D. Domingo de Zúñiga y Tovar, Contador mayor de la Contaduría de Hacienda; D. José Palacios Santander, Superintendente de Correos de Reino e, igualmente, contador mayor de la Contaduría de Cuentas de Hacienda hasta su muerte en $1765^{276}$. La Contaduría mayor parece privatizada, como vemos, en la primera mitad del siglo XVIII a manos de numerosos regidores de Guadalajara. Otros dos regidores accedieron a los Consejos de Castilla o Hacienda tras el paso por varios corregimientos: D. Agustín Caniego de Guzmán fue, en 1719, corregidor, alcalde mayor y superintendente de rentas de Cuenca y su provincia ${ }^{277}$, antes de ser consejero de Castilla y D. Bernardo de Rojas y Contreras, que accedió en 1765 a consejero de capa y espada, tras ejercer las intendencias de Guadalajara, Murcia y Córdoba ${ }^{278}$; y finalmente, D. Lucas Palomeque de Céspedes quien en 1766, cuando accede al oficio de regidor, aparece como un simple abogado para llegar a ser nombrado, en 1797, Director General de Correos y Caminos del Reino, con honores de intendente de Ejército y consejero de Hacienda ${ }^{279}$.

Al Consejo de Navarra, como fiscal y oidor, perteneció D. Vicente de Bedoya y Ossorio y su sobrino D. Pedro de Bedoya fue fiscal, asimismo en la Audiencia y Chancillería de la ciudad de Méjico, presente en Guadalajara desde su jubilación en 1750 , ambos con una buena formación letrada ya que eran previamente abogados.

273 A.H.N. Consejos. Legajo 11.520

${ }^{274}$ Caro Baroja, J.: Op. Cit. Págs. 184-188.

275 Junto con el Marqués de las Hormazas, Cabarrús y Drouvilhet era uno de los firmantes de todas las acciones emitidas. Real Cédula de 1782 por la que se crea el Banco Nacional de San Carlos. A.M.GU. Cosida en el Libro de Acuerdos de 1782

276 A.H.P.M. Protocolo 16.883. Fols 332-333 r.

277 A.H.P.GU. Protocolo 842. Fol 69-70 r.

278 ABBAD, D y OzANAM. D.: Les Intandents...Op. Cit. Pág. 168.

279 Se recibió carta notificando el nombramiento en el Ayuntamiento de Guadalajara el 22 de noviembre de 1797. A.M.GU. Libro de Acuerdos de 1797.

Hispania, LXII/2, núm. 211 (2002) 693-746 
Parece que sólo en pocos casos, las solidaridades regionales y familiares - $\tan$ presentes, según Fayard, entre los consejeros de Castilla ${ }^{280}$ — estuvieron presentes en los regidores del Consejo de Hacienda, porque la mayoría tenían el oficio por vía de venalidad. D. Juan de Orcasitas y Avellaneda accedió al oficio por herencia de su hermano $\mathrm{D}$. Lucas, pero al igual que aquél y su otro hermano mayor, $\mathrm{D}$. Francisco, los asientos están en el origen de su nombramiento como consejero, especialmente por abastecer al ejército de Felipe $V^{281}$ y el hijo del primer Conde de Moriana no hizo más que seguir con el oficio de su padre. También en la riqueza del poderoso banquero y asentista $\mathrm{D}$. Juan de Goyeneche hay que ver la compra del puesto de su hijo, D. Francisco Javier, como ministro de capa y espada, y tesorero en el Consejo de Indias, pero su influencia económica y política en la Corte ${ }^{282}$ sí que debió influir para conseguir para sus sobrinos, los Iriberri ${ }^{283}$, los cargos del Consejo de Hacienda. En el caso de D. Domingo de Zúñiga parece que la influencia del padre, $D$. Luis, primer Marqués de la Ribera, gentilhombre de boca del Rey fue decisiva para su acceso al Consejo de Hacienda ${ }^{284}$. Y, exceptuado el caso de Ruiz Mazmela, diputado en la Sala de Millones por sorteo, en el resto de los casos parece que se ascendió paso a paso desde peldaños más bajos, como el de los dos corregidores, Caniego de Guzmán y Rojas Contreras, que recibieron el nombramiento de consejeros al final de su carrera, o el de los dos fiscales Bedoya desde su formación letrada como abogados. El ejemplo más gráfico fue Palomeque quien, en 1766, cuando solicitó el título de regidor era un simple abogado, en 1772 ejercía la Primera abogacía suprema de Castilla, León y Aragón, y teniente de Fiscal de alcabalas, cientos y millones de Madrid y su partido ${ }^{285}$ pasó después a oficial del Archivo de la Secretaría de Hacienda, hasta su nombramiento como Director General de Postas y Caminos y consejero de Hacienda a fines del siglo XVIII.

$\mathrm{Al}$ menos otros seis regidores ejercieron un oficio cortesano en Palacio, como mayordomos de semana, gentileshombres de boca o de Cámara del Rey, caballerizos del Rey, la Reina o las infantas, y en estos casos sí accedieron por

${ }^{280}$ FAYARD, J.: Op. Cit., págs 207-264.

281 Según han demostrado Bravo Lozano, J. y Sanz Ayán, C.: Op. Cit., págs 423, 424 y 425, D. Francisco fue el primero que empezó con la administración y arrendamiento, bajo asiento, de la renta del pescado en los años 60 del siglo XVII, D. Simón comenzó con la administración de las Salinas de Galicia y después de las fianzas de las rentas del Reino, y D. Francisco, ya titulado Conde de Moriana, tuvo un papel fundamental en el abastecimiento del ejército de Felipe V.

${ }^{282}$ No sólo aparece como asentista de madera para la Armada desde 1697, sino que antes ejerció como administrador de los gastos secretos de Carlos II, tesorero de su mujer $\mathrm{D}^{\mathrm{a}}$ Mariana de Neoburgo y después lo será de las mujeres de Felipe V María Luisa de Saboya e Isabel de Farnesio, hasta su muerte en 1735. Caro Baroja, J.: Op. Cit., págs 100 a 116

283 También navarros.

${ }^{284}$ Tenía otro hermano consejero de Indias, D. Diego de Zúñiga y Tovar.

285 A.M.GU. Libro de Acuerdos de 1772. 
méritos de sus padres y familiares ${ }^{286}$. Ya hemos visto el caso del Conde de Saceda, gentilhombre de Cámara del Rey, pero hay que añadir los casos de D. Melchor Calderón de la Barca ${ }^{287}$ y D. Francisco Javier Monge y Urbina, gentileshombres de boca del Rey ${ }^{288}$ y los del austracista D. José de Torres y Morales, primer Vizconde de Irueste, caballerizo de Doña Mariana de Neoburgo (lo que tal vez justificase su partido por el pretendiente austríaco). D. Juan Francisco Remírez de Baquedano, Marqués de Andía y de la Ribera fue caballerizo de las Infantas y de la Reina Isabel de Farnesio y finalmente mayordomo de semana de los Reyes Felipe V y Fernando VI. D. Antonio de Iriberri fue paje del rey entre 1726 hasta 1733 en que se le concedió la plaza de caballerizo del Campo del Rey ${ }^{289}$. Los oficios de Corte eran muy apetecibles porque además de la remuneración económica (que no parece excesivamente grande ${ }^{290}$ ) y el prestigio social conferían cierta privanza al lado de la Monarquía y se estaba en el centro de decisión y poder más importante en el Antiguo Régimen: la Corte ${ }^{291}$.

Exceptuando los militares, escasos en el regimiento de Guadalajara (7 casos) y descontando el caso del Teniente Coronel D. Alberto Arias del Hierro no eran de muy alta graduación (eran el capitán de Marina D. Manuel Ruiz de Mazmela Castellanos, y los también capitanes D. Juan Nepomuceno de Rosales, D. Antonio de Obregón y Hontañón, capitán de Caballería en el Regimiento de Inválidos de Zamora, D. Antonio de Hierro y Herrera, y D. Pío Quinto del Río, capitán del Regimiento de milicias provinciales de Sigüenza, y D. Francisco Javier Sánchez Holguín, ayudante mayor de las milicias provinciales de Sagovia), el resto de los oficios lo copaba un amplísimo grupo de pequeños burócratas, abogados, escribanos, administradores de rentas, contables

\footnotetext{
${ }^{286}$ Para las características de estos cargos y la composición de la Corte española en el siglo XVIII véase GómeZ-Centurión JimÉnez, C.: «La herencia de Borgoña: Casa Real española en el siglo XVIII», en Torre de los Lujanes, $\mathrm{n}^{\circ} 28$, Madrid, 1994. Págs 61 a 72.

${ }^{287}$ Gentilhombre de boca supernumerario desde 1739. En 1744 solicita una plaza definitiva, con dotación de gajes y sueldo. La recomendación es del Duque de la Mirándola. A.G.P. Caja $12.960 / 4$.

${ }^{288}$ Que recibió la plaza de gentilhombre de boca en situación de supernumerario, sin gajes ni sueldo el 18 de abril de 1791, y una plaza definitiva el 27 de octubre de 1793 . Para ello expuso los méritos de su padre y su abuelo, ambos regidores de Guadalajara, y su participación en la proclamación al trono de Carlos IV dónde «..concurrió de principal Comisario a besar Vra Real Mano y de la Reina..». A.G.P. Caja 694/3.

${ }^{289}$ A.G.P. Caja 12.906/5. La recomendación fue presentada por los méritos de su padre.

290 Según GomeZ-CENTURION, pág. 63, en la primera mitad del siglo XVIII cobraban unos 5 reales diarios, menos salario que un oficial tejedor de sarguetas de la Real Fábrica que, según el Catástro de Ensenada, en 1751, cobraba 6 reales diarios. Guadalajara, 1751 ..., pág. 105. Sabemos que el sueldo anual de D. Francisco Javier Monge, en 1793, era de 5.500 reales. A.G.P. Caja 694/3.

${ }^{291}$ Como afirma GómeZ-Centurión JiméNeZ, C.: Op. Cit. pág. 62.»Constituía una gran bolsa de cargos, mercedes y pensiones en torno a la cual era posible aunar $y$ concertar intereses contrapuestos $y$ alianzas, poniéndose al servicio de la Monarquía».
} 
y oficiales de la Casa del Infantado, en un total de 35 regidores, la mayoría de los que ejercían otro oficio.

Empecemos por los oficiales de la Casa del Infantado, presentes en el concejo de Guadalajara en un número no menor de 10 regidores en el periodo estudiado. Se reclutaban entre los servidores personales del X Duque o la XI Duquesa, y su nombramiento como tenientes respondía a una recompensa por sus servicios, a la vez que velaban por los intereses de la Casa en la ciudad de Guadalajara a donde normalmente se desplazaban. En la Secretaría personal y de cartas estuvieron los 3 miembros de la familia Baraya que ejercieron un regimiento en Guadalajara (D. Lucas, D. Francisco y D. José Nicolás), y también D. Gaspar de Ceballos Barreda y D. Manuel de las Doblas y Zúñiga, abogado. D. Diego Fernández de la Madrid y D. Pedro de Loaysa fueron gentileshombres de Cámara del Duque; D. Juan Antonio de Otazo camarero y mayordomo mayor del Duque 292 , al igual que D. Francisco Ortega de Castro ${ }^{293}$, mientras que su sobrino, D. José Ortega de Castro, fue mayordomo y administrador de las rentas e intereses de Duque en el partido y señorío de Jadraque y D. Juan Antonio Morales Coronel fue corregidor y administrador de rentas del partido y señorío de Hita.

Otro grupo numerosísimo eran los contables, oficiales y burócratas en la administración provincial de las rentas reales, en la del tabaco, los millones, las alcabalas, etc: al menos 12 regidores (algo más del 10\%), de los que 4 estaban al servicio de la administración de la Real Fábrica de Paños ${ }^{294}$. Estos sí solían compaginar su oficio con el regimiento, aunque su ocupación les llevase a incurrir en provisionales periodos de absentismo. Buen número de estos oficios eran cargos venales, privatizados en familias de regidores, como la Depositaría general, que llevaba asociado el regimiento, la Contaduría de millones, perteneciente a los Torres Contreras, o el Alguacilazgo de millones ${ }^{295}$ que ejercieron los Urbina, pero otros pertenecían a la Administración de rentas provinciales, como D. Bernardo García Caltañazor, contador en 1773, D. Francisco Javier Morales Salomón, oficial en la administración de la renta del tabaco. y de D. José González de Mendoza, oficial de la renta de Correos en Alcalá de Henares ${ }^{296}$. Todos presentes en el regimiento de Guadalajara, curiosamente, después

${ }^{292}$ La organización de las grandes Casas nobiliarias, entre ellas la del Infantado seguía una estructura interna parecida a la de la Corte, con un verdadero enjambre de oficiales y servidores. DoMíngUez ORTIZ, A.: Las clases privilegiadas... Op. Cit., págs 151 y 152.

293 A.H.P.M. Protocolo 15.434, fols 111-115 r.

${ }_{294}$ D. Miguel de Torres Contreras, Contador también de millones de Guadalajara, su hijo D. José de Torres Medrano y D. Ramón de Arguedas oficiales, igualmente, en la Contaduría de las Reales Fábricas y D. Diego de Pedroches, administrador provincial, en 1770, de las Reales Fábricas y de su almacén de paños en Madrid.

${ }^{295}$ Ya estudiados anteriormente por lo que no me extenderé ni en sus características, funciones ni en sus propietarios o servidores.

296 A.M.GU. Libro de Acuerdos de 1773. Callejero realizado el 17 de mayo de 1773, 
de 1766 y al que accedieron, en su mayoría, por compra, lo que demuestra el interés de estos pequeños burócratas por el oficio municipal en la segunda mitad del siglo XVIII. Cuatro regidores fueron abogados ${ }^{297}$, y otros tres habían sido escribanos, dos de Madrid (el ya comentado Caltañazor entre 1744-1751, antes de incorporarse a la administración de las rentas provinciales en Guadalajara y D. Gaspar de Caballos Barreda, entre 1687-1721 antes de ejercer la secretaría de la Casa del Infantado) y uno en Guadalajara, D. Pedro de Montoya, que ejerció incluso la escribanía del Ayuntamiento en los periodos que no fue teniente de regidor, ya que la legislación prohibía ejercer a la vez un regimiento y una escribanía ${ }^{298}$, cifra insignificante en comparación con sus antecesores porque los hijos y nietos de escribanos de Guadalajara, especialmente de Ayuntamiento, del siglo XVII estuvieron bien presentes en el Concejo del XVIII: los Oñez descendían del escribano de Ayuntamiento Francisco Oñez de la Torre, los Fernández de Lasarte, descendientes del también escribano de Ayuntamiento Pedro Fernández, los Suárez Salazar del escribano Francisco Suárez Salazar, los Yanguas del escribano de padrones Diego de Yanguas, los Martínez de Torices de los Torices. Igualmente fueron hijos de escribanos, ya en el siglo XVIII, D. Manuel Parrales, hijo de Francisco Parrales, D. Bartolomé Clavero hijo de Francisco Clavero y los Montoya del escribano de Ayuntamiento D. Pedro Sánchez de Montoya. En total 15 regidores de los 115 del periodo estudiado tuvieron padres, abuelos o bisabuelos escribanos de Guadalajara.

Muchos regidores estaban dedicados a la administración y recaudación de rentas particulares, especialmente de los diezmos o el excusado del Arzobispado de Toledo (jurisdicción eclesiástica a que pertenecía la mayoría de la provincia de Guadalajara), actividad que parece muy lucrativa y unos 6 regidores ejercieron la mayordomía de estos impuestos religiosos: así D. Manuel Fernández de Lasarte, en 1696 aparece como administrador de todas las rentas del Arcedianato de Guadalajara y administrador y mayordomo de los diezmos del Arzobispado en los partidos de Uceda y Buitrago ${ }^{299}$ y en 1715 lo era además del Valle de Lozoya, para lo que hipotecó 114.000 reales en bienes raíces; en 1721 aparece con su hijo D. Antonio Fernández de Lasarte, quien era mayordomo de rentas del excusado del Arzobispado de Toledo en esos mismos parti$\operatorname{dos}^{300}$ y que en 1724 sustituyó a su padre en la administración ${ }^{301}$. También la familia Monge de Soria ejerció durante tres generaciones la administración de

\footnotetext{
297 Los ya comentados Palomeque de Céspedes y D. Manuel de las Doblas, Secretario y administrador del Palacio del Infantado para la Duquesa y los licenciados D. Gerónimo de Zaldívar y Orbe y. D. Manuel Clavero.

${ }^{298}$ Fue en las Cortes de 1570 cuando se acordó que no pudiesen ser regidores quienes hubiese sido mercaderes por su persona, oficial mecánico o escribanos, aunque sí sus hijos. DomínguEZ ORTIZ, A.: «La venta de cargos públicos en Castilla...» Op. Cit., pág. 154.

299 A.H.P.GU. Protocolo 853. 24 de enero de 1696.

300 A.H.P.GU. Protocolo 843. 16 de enero de 1721.

301 A.H.P.GU. Protocolo 884. 23 de julio de 1724
}

Hispania, LXII/2, núm. 211 (2002) 693-746 
los diezmos de dicho Arzobispado en otros partidos: D. Felipe Monge de Soria lo era del partido de Brihuega, en 1701, para lo que hipotecó 22.000 reales propios y otros 38.700 de otros parientes ${ }^{302}$, y en 1704 lo era del de $\mathrm{Hita}^{303}$. Su hijo D. Bernardo Monge de Soria lo fue del de Santorcaz, en donde fue también corregidor por nombramiento del Arzobispo en los años 60 del siglo XVIII ${ }^{304}$, y el hijo de éste, a su vez, le sucedió en 1764305 y fue nombrado mayordomo de rentas decimales del partido de Alcalá de Henares en 1777306. En la mayordomía de rentas decimales del partido de Guadalajara estuvieron los Morales Coronel, D. Juan Antonio - que ya había sido a mediados de siglo Alcalde mayor de Hita y mayordomo de rentas de la Casa del Infantado 307 - y su hijo D. Vicente, quien en 1780 hipotecó el cargo con bienes raíces de su primo, el clérigo y regidor D. José Díaz Coronel, tasados 260.105 reales $^{308}$; D. Manuel Parrales fue el recaudador y colector del subsidio y excusado de Guadalajara y su Arciprestazgo desde 1717, con la función de cobrar este impuesto religioso a curas, beneficiados y capellanes y demás religiosos por repartimiento ${ }^{309}$, y en 1806 D. Gerónimo Páez Xaramillo hipotecó los bienes de su mujer tasados en 133.803 reales para la administración del excusado de Guadalaja$\mathrm{ra}^{310}$. La administración de las rentas parece muy rentable y conocemos los ingresos anuales que dejaba a algunos regidores: D. Antonio Fernández de Lasarte cobraba, según el Catastro, en $1751,11.000$ reales anuales por su administración de diezmos en el partido de Guadalajara ${ }^{311}$, y D. Francisco Javier Monge y Urbina, en 1770, 6.600 reales por las de Uceda y Santorcaz ${ }^{312}$. Otros 6.600 reales al año cobraba de la Casa del Infantado D. Juan Antonio Morales Coronel en 1752 por la mayordomía de las rentas y el Corregimiento, en $\mathrm{Hita}^{313}$, y, en 1728, el documento notarial por el que D. José Ortega de Castro afianza sus bienes para la mayordomía de rentas de la casa del Infantado en Jadraque y su partido nos habla de un salario de 600 maravedís al día (cerca de 6.500 reales de vellón al año) ${ }^{314}$.

302 A.H.P.GU. Protocolo 4061/13. 13 de febrero de 1701.

303 A.H.P.GU. Protocolo 854.

${ }^{304}$ A.H.P.GU. Protocolo 970. 22 enero de 1763.

30s Para lo que hipotecó 97.000 reales. A.H.P.GU. Protocolo 1.015. 22 septiembre de 1764.

306 A.H.P.GU. Protocolo 993, fols 258-269 r.

307 A.H.P.GU. Catastro. Legajo 703. Familias de legos. 1752.

308 A.H.P.GU. Protocolo 1.668. 17 de noviembre de 1780.

${ }^{309}$ Hipotecó con su mujer y el regidor D. Juan de la Peña bienes raíces por 68.550 reales. A.H.P.GU. Protocolo 872, fols 368 r-377 v. En 1758 supusieron, en todo el Arciprestazgo de Guadalajara, 46.339 reales y 28 maravedís. Ibidem. Protocolo 923 . fols 186-188 r.

310 A.H.P.GU. Protocolo 1.005, fol. 51 r.

311 A.M.GU. Legajo 1H.82-a.

312 A.M.GU. Legajo 1 H.75-a.

313 A.H.P.GU. Catastro. Legajo 705. Hita, fol. 23 r.

${ }^{314}$ A.H.P.GU. Protocolo 2.409, folio 238 r.

Hispania, LXII/2, núm. 211 (2002) 693-746 
Algunos otros regidores fueron síndicos y mayordomos de conventos e iglesias de Guadalajara, como D. Ceferino Oñez, mayordomo de la iglesia de San Nicolás en 1796 y D. Juan Fernández de Lara del convento de San Francisco de Guadalajara, a quien por su administración de quince años, entre 1782 y 1797 , le debían 17.518 reales $^{315}$.

No parece que Fernández de Lara perdiera oportunidad de estar cerca de caudales públicos o privados; asentista de leñas de Guadalajara y de la Reales Fábricas hasta que ejerció el regimiento, administró durante años los bienes de dicho convento y también las rentas de las posesiones del Marqués de Villamejor en la provincia de Guadalajara. Fernández de Lara (sin «don» en 1767, en los primeros documentos públicos en que aparece), sobrino del comerciante lonjista y antiguo mayordomo de propios municipales Gregorio Navarro, fue un activo asentista en el ámbito urbano de Guadalajara ${ }^{316}$. Inició una carrera económica y social que le llevó a ejercer, tras perder el asiento de la fabricación de carbón de los montes propios de la ciudad entre 1767 y $1783^{317}$ (aunque continuó el de las Reales Fábricas que tenía, al menos desde, 1776) ${ }^{318}$, el empleo de Síndico Personero del Común en 1783; posteriormente, en mayo de dicho año, consigue un regimiento como teniente del Marqués de Villamejor (de quien era su administrador de rentas) que ejerció hasta 1793 , año en que compró un regimiento propio por 15.500 reales a la viuda del regidor González de Mendoza ${ }^{319}$. Junto con los Puche, padre e hijo, son los únicos ejemplos de regidores presentes en el Concejo de Guadalajara del siglo XVIII con actividades económicas especulativas basadas en asientos, y nos hemos detenido en él por la proximidad al Ayuntamiento en sus operaciones comerciales, sin el cual no hubiera obtenido los substanciosos beneficios económicos de sus asientos ni el prestigio social derivado de la pertenencia al Cabildo municipal.

Los regidores D. Antonio Puche Doncel y D. Antonio Puche Quintana, - encargados del abastecimiento y provisión de abastos a los Reales Presidios de Africa, del tren ${ }^{320}$ de artillería en las campañas militares de Navarra, Cataluña y Ceuta desde 1719 a 1721, arrendadores y administradores de las rentas reales y los millones del Reino de Toledo entre 1721 y $1725^{321}$ y encargados de la fabricación de fusiles para el Ejército en la fábrica de Silillos (y que falleció sin cumplir el asiento) - no parece que tuvieran la suerte de Lara, porque sus operaciones económicas no salieron especialmente bien, ya que en 1730 las deudas

315 A.H.P.GU: Protocolo 1.078, fols 248-249 r.

316 A.H.P.GU. Protocolo 971, fols 16 r y ss. y Protocolo 1.006. 30 de septiembre de 1779)

317 Ello no le impidió realizar otras actividades económicas, como en 1780 que recibió la obligación del abasto de carne de vaca, bajo régimen de monopolio por el Ayuntamiento (A.H.P.GU Protocolo 1.043 , fols $236-237$ r.)

318 A.H.P.GU. Protocolo 1.006, s/f, 30 septiembre de 1779.

319 A.M.GU. Libro de Acuerdos de 1793. Título de 29 de agosto de 1793.

320 Máquinas y otros instrumentos útiles para el transporte de la artillería.

321 A.H.P.M. Protocolo 15.505 , fols 52 a 54 r, y 256 r-vto. 
ascendían a 1.279 .138 reales. $^{322}$, y desde 1727 (año de la muerte de D. Antonio Puche Doncel) sus bienes fueron embargados (un arrendamiento no pagado suponía un embargo de bienes) y fueron concursados y entregados a diversos acreedores hasta 1768 , en que se vendieron para pagar las deudas ${ }^{323}$.

Como un próspero comerciante, con lonja abierta en la ciudad aparece D. Juan Francisco de Udaeta, que presentó como avales para obtener el título de regidor y Depositario General de Guadalajara una casa-posada tasada en 1.027.797 reales y 15 maravedís 324 y encontramos un arquitecto, D. Manuel Bradi, que figura con el título de maestro de obras de Madrid aprobado por la Real Academia de Artes de San Fernando en 1793, en los papeles que presentó en el Ayuntamiento de Guadalajara demostrando su hidalguía ${ }^{325}$.

Curiosa es la condición social de dos regidores, D. Fernando Caniego y Araque, colegial y clérigo de «órdenes menores» en $1751^{326}$ y de D. José Díaz Coronel, presbítero en el vecino pueblo de Yunquera de Henares, a quién, aunque estaba prohibido el ejercer el regimiento a los miembros del estamento religioso, se le habilitó excepcionalmente su título para «el ejercicio de su oficio no obstante cualesquier leyes y pragmáticas destos Reynos» ${ }^{327}$. Eso sí, no participó en ninguna sesión municipal, exceptuando las que se hicieron para el sorteo a la Diputación del Reino cada seis años.

En resumen, aparentemente el Ayuntamiento de Guadalajara en el siglo XVIII podría definirse como un Ayuntamiento nobiliario porque, en teoría, se presuponía la condición nobiliaria a todos los miembros del Cabildo municipal de Guadalajara: 104 de los 115 regidores, algo más del 90\%, tienen documentada su condición noble, pero hemos de tener en cuenta varios aspectos:

a. La presencia de la alta nobleza es escasa (un 16\%), sobre todo teniendo en cuenta que el absentismo entre los regidores titulados fue casi total dada su condición de consejeros, cortesanos o sencillamente desinteresados en el ejercicio de la acción municipal. Sólo cinco de los regidores titulados ejercieron el oficio y no siempre en periodos largos de tiempo: D. Domingo de Zúñiga, Marqués de la Ribera, D. Juan Francisco Remírez de Baquedano, asimismo Marqués de la Ribera y de Andía, El Conde de la Vega y del Pozo, D. Francisco Javier de Dicastillo (los tres Alféreces mayores), y los Marqués de Villamejor, D. José Zósimas de Torres y su

\footnotetext{
322 Ibidem, fols 564-567 r.

323 A.H.P.M. Protocolo 19.696, fol. 520 r y ss. Escritura de venta del señorío y propiedades de Camarma de Esteruelas y Villaviciosa.

${ }^{324}$ A.H.P.GU. Protocolo 1.095, fols 106-109 r.

325 A.M.GU. Libro de Acuerdos de 1789, s/f.

326 A.H.P.GU. Legajo 660. Catastro. Relación de Legos. Libro II, folio 741.

327 A.M.GU. Libro de Acuerdos de 1752. Sesión de 17 abril. 
hijo D. José de Torres y La Cueva. El resto no apareció por la ciudad, a veces ni para la toma de posesión.

b. Los simples caballeros de Ordenes militares (poco más del 10\%) igualmente fueron, en su inmensa mayoría, absentistas en el oficio, muchos de ellos por su condición de servidores de la Casa del Infantado, en Madrid.

c. Quienes participaron activamente en el Ayuntamiento fueron los sectores sociales medios urbanos siendo un grupo amplio, cerca de un $75 \%$ del total de los 115 regidores. De ellos 48, son simples hidalgos y otros 10 , no tienen definida su condición nobiliaria, pero ambos provienen de los mismos sectores socio-profesionales: hijos de regidores, escribanos, oficiales y burócratas, ellos mismos, al servicio de la administración de rentas provinciales, del Arzobispado de Toledo y de la Real Fábrica de Paños.

Esa es la verdadera naturaleza de la oligarquía urbana en la Guadalajara del siglo XVIII: la ciudad está en manos de un pequeño grupo de oficiales, contables, administradores, funcionarios y burócratas, un grupo social que, en un análisis de clases, podría definirse de pequeña burguesía urbana, con fortunas medias $^{328}$, basadas en el disfrute de pequeños mayorazgos no muy rentables en general y, sobre todo, en sus salarios, cuya rígida escala de valores y mentalidad conservadora imprimirán carácter, al menos durante siglo y medio, a la ciudad $^{329}$.

${ }^{328} \mathrm{La}$ fortuna media basada en 29 casos de regidores de los que conocemos sus inventarios de bienes libres o la tasación de los bienes inmuebles presentados como avales en hipotecas, y descontados los títulos y los consejeros en Hacienda o Castilla, es de unos 250.000 reales.

329 Desaparecida la Fábrica de Paños a principios del siglo XIX, y con ella el primer grupo social de los obreros industriales, Guadalajara no iniciará la industrialización, y con ella el desarrollo demográfico, económico y urbano hasta los años 60 del siglo XX. 
RELACION DE REGIDORES DE GUADALAJARA ENTRE 1718-1800.

(Por orden de antigüedad en la posesión)

1-D. Juan de Cáceres.

$14 / 11 / 1677-1724 \quad$ B.D

2- D. José de Obregón Hontañón.

$24 / 10 / 1678-1726 \quad$ B.D

3- D. Gerónimo de Urbina Pimentel.

$31 / 10 / 1678-1729$

$\mathrm{P}$

4- D. Lope Suárez Salazar

$23 / 11 / 1679-1718$

5- D. Domingo de Zúñiga y Guzmán.

Cab. de Santiago II Marqués de la ribera.

$22 / 12 / 1687-1719 \quad T$

6- D. Pedro Vázquez Garay.

$26 / 02 / 1690-1724 \quad \mathrm{P}$

7- D. Felipe Monge de Soria. Cab. de Santiago.

$05 / 12 / 1694-1722$

$\mathrm{P}$

8 D. Luis Arellano Pacheco.

II Marqués de Villatoya.

9- D. Manuel Fernández de Lasarte.

10- D. Alfonso de Medrano Mendoza.

$17 / 09 / 1696-1730 \quad P$

$20 / 02 / 1697-1724 \quad T$

$18 / 03 / 1697-1728 \quad \mathrm{P}$

11- D. Agustín Caniego Guzmán. Cab. Calatrava.

$10 / 06 / 1698-1731 \quad P$

12- D. Juan Orcasitas Avellaneda. Cab. Alcántara. I Conde de Moriana.

$07 / 08 / 1702-1726 \quad P$

13- D. José. A. de Torres Messía Morales,

I Vizde de Irueste, I Marqués de Villamejor.

22/08/1702- $1706 \quad P$

$01 / 03 / 1703-1726 \quad P$

05/08/1704-1734 P

14-D. Diego de Yanguas Ortiz de Lasarte

$10 / 06 / 1709-1732 \quad P$

16- D. Vicente de Bedoya Osorio

$27 / 03 / 1709-1757$

$P$

17- D. Manuel Parrales

Desde $1710-1726 \quad T$

18- D. Luis Verdugo

19- D. José Solís de Magaña

$22 / 02 / 1710-1738$

$P$

20- D. Juan Antonio de Otazo. Cab. de Santiago.

$23 / 08 / 1713-1719$

$\mathrm{T}$

$12 / 05 / 1714-1740 \quad P$

21-D. Manuel Martínez de Torices

$30 / 05 / 1714-1720 \quad \mathrm{~T}$

22- D. Juan Martínez de Torices

$12 / 06 / 1714-1768 \quad P$

23- D. José Palacios Santander. Cab. Calatrava.

24- D. Sebastián Francisco de Sola

25- D. Lucas de Baraya y Olea. Cab. Alcántara

$07 / 09 / 1715-1734 \quad T$

$20 / 05 / 1716-1752 \quad T$

26-D. José Oñez de la Torre

27- D. Juan de la Peña.

$17 / 12 / 1717-1756 \quad P$

$07 / 07 / 1718-1740 \quad$ R

28- D. Francisco Ortega de Castro.

Caballero de Calatrava.

$16 / 12 / 1719-1728$

$\mathrm{T}$

Hispania, LXII/2, núm. 211 (2002) 693-746 
29- D. Juan $\mathrm{Fc}^{\circ}$ Remírez de Baquedano.

II Marqués de Andía, III Marqués de la Ribera $\quad 21 / 12 / 1719-1725 \quad$ T

30- D. Pedro de Loaysa. Caballero de Santiago.

31- D. Manuel Suárez Salazar

$20 / 02 / 1720-1741 \quad T$

$16 / 05 / 1720-1742 \quad P$

$03 / 12 / 1720-1728 \quad P$

$17 / 03 / 1722-1762 \quad P$

33- D. Bernardo Monge de Soria. Cab. Santiago

34- D. F. J de Goyeneche. Caballero Santiago

I Marqués de Belzunce

24/03/1722-1748 P

24/07/1722-1728 P

$05 / 08 / 1722-1723 \quad T$

13/08/1722 - $1763 \quad \mathrm{P}$

26/09/1724-1735 T

38- D. Juan de Salazar. Cab. de Santiago.

39- D. Francisco Javier López de Dicastillo.

Cab. de Santiago, III Conde de la Vega del Pozo.

40- D. Diego Antonio de Yanguas

$28 / 02 / 1725-1758 \quad \mathrm{~T}$

$14 / 02 / 1726-1762 \quad \mathrm{P}$

26/02/1726-1735 P

$13 / 03 / 1727-1752 \quad \mathrm{P}$

01/03/1727-1762 P

43- D. Miguel de Torres y Contreras

44- D. Diego Fernández de la Madrid. Caballero de Calatrava

45- D. José Ortega de Castro.

46-D. José de la Cámara Reynoso

$25 / 05 / 1728-1738 \quad \mathrm{~T}$

$25 / 05 / 1728-1745 \quad \mathrm{~T}$

$08 / 06 / 1728-1762 \quad T$

47- D. Juan de Orcasitas Oleaga.

II Conde de Moriana Caballero de Alcántara

48- D. Antonio Puche Quintana

49- D. Alfonso de Urbina Pimentel

$22 / 06 / 1728-1738$

$\mathrm{P}$

$15 / 07 / 1728-1748 \quad P$

$29 / 11 / 1729-1757 \quad P$

$19 / 12 / 1729-1743 \quad P$

51- D. Alonso de Arellano. III Marqués de Villatoya.

$25 / 08 / 1730-1768$

$11 / 04 / 1731-1734 \quad \mathrm{P}$

Cab. de Santiago. I Marqués de Valbueno.

53- D. Fernando Caniego y Araque.

$22 / 04 / 1731-1762$

$P$

54- D. Antonio de Iriberri Lastiri. Cab. Santiago.

II Marqués de Valbueno

18/02/1734-1755 P

29/01/1734-1754 T T

56- D. Manuel $\mathrm{M}^{\mathrm{a}}$ de Torres Dávalos. II Vizconde Irueste.

57- D. Antonio Fernández de Lasarte.

58-D. Gaspar de Ceballos Barreda

59- D. Francisco Miguel de Goyeneche.

Cab. de Santiago. I Conde de Saceda.

28/05/1734-1756 P

$25 / 11 / 1735-1760 \quad P$

$29 / 07 / 1738-1750 \quad \mathrm{~T}$

$08 / 03 / 1740-1762 \quad P$

Hispania, LXII/2, núm. 211 (2002) 693-746 
60- D. Pedro de Bedoya Osorio

$\begin{array}{ll}07 / 06 / 1741-1757 & \text { P } \\ 04 / 11 / 1742-1772 & \text { P } \\ 05 / 09 / 1743-1780 & \text { P } \\ 23 / 12 / 1743-1777 & \text { P } \\ 26 / 11 / 1744-1774 & \text { P } \\ 28 / 04 / 1745-1753 & \text { T } \\ 18 / 08 / 1745-1786 & \text { T } \\ 15 / 07 / 1749-1768 & \text { T } \\ 02 / 01 / 1751-1768 & \text { T }\end{array}$

61- D. Juan de Dios Gamboa y Torres

62- D. José Díaz Coronel

63- D. Juan Bautista Clavero y Sesse

64- D. Isidro Castellanos y Heredia

65- D. Francisco de Baraya y Larrabe

66- D. Gerónimo de Zaldívar y Orbe

67- D. Juan Ant ${ }^{\circ}$ Morales Díaz Coronel. Caballero de Santiago.

68- D. Manuel de las Doblas y Zúñiga

69- D. D. Bernardo de Rojas Contreras.

Caballero de Calatrava.

$13 / 03 / 1752-1758 \quad$ B.D

70 - D. José de Bedoya Díaz

71- D. Antonio de Medrano y Mendoza

$11 / 04 / 1752-1783$

T

72- D. Fausto de Zaldívar

73- D. Fermín de Bedoya Osorio

$07 / 07 / 1754-1787$

$\mathrm{T}$

$09 / 06 / 1755-1776$

$P$

$09 / 09 / 1757-1800$

$\mathrm{P}$

74- D. Félix de Urbina Pimentel

$14 / 021758-1765$

$P$

75- D. Diego de Pedroches Astaburuaga

$18 / 04 / 1758-1791$

R y $P$

76. D. Melchor Calderón de la Barca

$08 / 11 / 1758-1762$

$\mathrm{T}$

77- D. Francisco José Oñez de la Torre

$26 / 03 / 1760-1799$

$\mathrm{P}$

78- D. José de Baraya y Lacampa

79- D. José de Priego

$26 / 03 / 1760-1768$

$\mathrm{P}$

80- D. Pedro Pacheco Caniego

$08 / 06 / 1762-1769$

$02 / 07 / 1762-1781$

$\mathrm{P}$

81- D. José de Torres Medrano

$01 / 09 / 1762-1775$

$\mathrm{P}$

82- D. Fco Javier Monge y Urbina

$22 / 12 / 1762-1799$

$P$

83- D. Bonifacio Pérez de Oñana

$08 / 05 / 1764-1799$

$\mathrm{P}$

84- D. José Antonio de la Peña

$01 / 04 / 1764$ - ?

$\mathbf{P}$

85- D. Pedro José de Montoya

86- D. Lucas Palomeque de Céspedes

$23 / 11 / 1766-1768$

$\mathbf{P}$

$01 / 02 / 1767-?$

$\mathrm{T}$

87- D. Juan Cristóbal Justiniani.

IV Marqués de Peñaflorida.

$24 / 07 / 1768-1797 \quad P$

88- D. Juan Javier Goyeneche, II Conde de Saceda,

II Marqués de Belzunce, Marqués de Ugena.

18/03/1770 - $1788 \quad P$

89- D. Joaquín Vicente de Borda y Goyeneche.

90- D. Ramón de Arguedas.

91- D. Bernardo García Calthañazor

92- D. Ceferino Oñez de la Torre

93- D. Manuel Ruiz de Mazmela. Caballero de Santiago.

$27 / 02 / 1773-1793 ?$

20/01/1774 - ?

$01 / 02 / 1774-1794$

$P$

$20 / 02 / 1774-1801$

$\mathrm{P}$

$12 / 07 / 1774-?$

$\mathbf{P}$

Hispania, LXII/2, núm. 211 (2002) 693-746 
94- D. José Zósimas de Torres Heredia.

II Marqués Villamejor.

95- D. Francisco Javier de Torres y Medrano

96- D. Pío Quinto del Río

97- D. Fc Javier Morales y Ramírez Salomón.

98- D. Manuel Clavero y Sesse

99- D. Tomás Fernández de la Oliva

100- D. Joaquín Pacheco Caniego Tizón

101- D. Juan Fernández de Lara

102- D. Vicente Morales Díaz Coronel

103- D. José González de Mendoza

104- D. José de Cáceres y Salinas

105- D. Juan Nepomuceno de Rosales

106- D. Pedro Sáenz de Pedroso

107- D. José de Torres y La Cueva.

III Marqués de Villamejor.

108- D. Juan Francisco de Udaeta.

109- D. Alberto Arias del Hierro.

110- D. Gerónimo Páez Xaramillo.

111- D. Domingo González Viejo

112- D. Francisco Javier Sánchez Holguín

05/03/1775- $1783 \quad P$

25/07/1775-1790 P

09/08/1778 - $1796 \quad$ B.D

22/12/1780 - ? P

desde 1781 - ? $\quad \mathrm{P}$

11/02/1781-1793 P

$06 / 12 / 1781-? \quad P$

22/05/1883-1793 T

$04 / 07 / 1783-$ ? $\quad \mathrm{P}$

$17 / 06 / 1783-1789 \quad P$

$15 / 02 / 1787-? \quad P$

21/07/1789 - ? T

$21 / 02 / 1794-1802 \quad$ B.D

26/04/1794-? P

$10 / 05 / 1794-? \quad P$

12/01/1795 - ? $\quad P$

$13 / 03 / 1795-? \quad T$

15/04/1795 - ? T

07/10/1796 - ? $\quad$ B.D

113- D. Manuel Bradi.

23/08/1797 - ? P

20/06/1799 - ? P

28/07/1799 - ? P

$(\mathrm{P})=$ En propiedad.

$(\mathrm{T})=$ Ejercido por tenientes.

$(B)=$ Renunciado provisionalmente por el propietario.

(B.D) $=$ Bienes dotales aportados por la mujer 